\title{
1 Environmental and geometric optimisation of cylindrical drinking water storage tanks
}

\section{David Sanjuan-Delmás ${ }^{a}$, Elena Hernando-Canovas ${ }^{b}$, Pablo Pujadas ${ }^{b}$, Albert de la Fuente ${ }^{b}$, Xavier}

3 Gabarrell ${ }^{a, c}$, Joan Rieradevalla,d ${ }^{a, \text { Alejandro Josa }}{ }^{\mathrm{e}, \mathrm{f}}$

4 a Sostenipra, Institute of Environmental Sciences and Technology (ICTA), Universitat Autònoma de Barcelona 5 (UAB), Campus UAB, 08193 Bellaterra, Barcelona, Spain. 2014 SGR 1412.

6 bepartment of Construction Engineering, Universitat Politècnica de Catalunya, UPC, Jordi Girona 1-3, 08034 7 Barcelona, Spain.

8 'Department of Chemical Engineering, (Catalan Biotechnology Reference Network -XRB-), Universitat Autònoma de Barcelona (UAB), Campus UAB, 08193 Bellaterra, Barcelona, Spain.

10 department of Chemical Engineering, Universitat Autònoma de Barcelona (UAB), Campus UAB, 08193 Bellaterra, 11 Barcelona, Spain.

12 e Department of Geotechnical Engineering and Geosciences, School of Civil Engineering, Universitat Politècnica de 13 Catalunya-Barcelona Tech (UPC), Barcelona, Spain.

14 Institute of Sustainability, Universitat Politècnica de Catalunya-Barcelona Tech (UPC), Barcelona, Spain.

15 *Corresponding author: David Sanjuan-Delmás, Sostenipra, Institute of Environmental Sciences and 16 Technology (ICTA), Universitat Autònoma de Barcelona (UAB), Campus UAB, 08193 Bellaterra, 
Urban water cycle construction processes are an important element to consider when assessing the sustainability of urban areas. The present study focuses on a structural and environmental analysis of cylindrical water tanks. The goal is to optimise cylindrical water tanks from both an environmental (environmental impacts due of life cycle assessment (LCA)) and a geometric perspective (building material quantities for construction purposes depending on the tank characteristics).

Methods

A sample of 147 cases was defined based on different positions (buried, superficial and partially buried), dimensions (combinations of heights and radii) and storage capacities (between 100 and 10,000 $\mathrm{m}^{3}$ ). A structural analysis was conducted for a defined set of cases to determine the quantities of steel and concrete required for its construction. The environmental impacts of the entire life cycle were assessed through a life cycle assessment (LCA). Additionally, environmental standards (the less impactful option for each dimension assessed: geometry, storage capacity and position) defined in the study were applied to realistic cases to evaluate potential environmental savings.

Results and discussion

The LCA shows that materials are the main contributor to environmental impacts (more than transport, installation and end of life life cycle stages). For this reason, the results of the structural and environmental assessments coincide. Taller water tanks have shown to be less impactful (60 to $70 \%$ less impact for a $10.000 \mathrm{~m}^{3}$ tank). Regarding the position, superficial water tanks have shown to have between 15 and 35\% less impact than buried ones. The environmentally preferred water storage capacity is between 1,000 and 2,500 $\mathrm{m}^{3}$, being between 20 and $40 \%$ less impact. For instance, an 8,000 $\mathrm{m}^{3}$ tank would emit $1,040 \mathrm{t}$ of $\mathrm{CO}_{2}$ eq. Applying the environmental standards $170.5 \mathrm{t}$ of $\mathrm{CO}_{2}$ eq could be saved (16\% of the total amount).

47 The results of this study show that among the cases analysed, superficially positioned cylindrical water tanks of $8.5 \mathrm{~m}$ in height and of between 1,000 and $2,500 \mathrm{~m}^{3}$ in storage capacity present fewer impacts. 
49 The use of these standards in municipal water tanks construction projects may significantly reduce 50 environmental impacts (10 to $40 \%)$ in all impact categories.

51 


\section{Introduction}

1.1 Urban water cycle and water supply

Water supplies constitute a basic global need for the development of communities. The urban water cycle (UWC) consists of a series of stages related to providing populations with water and to evacuating wastewater and excess rainwater (UNESCO, 2012). Water is treated after its abstraction from the environment to reach a required potable level and is then transported to a consumption point. It then undergoes sewerage and is treated again before being returned to the environment or reused.

Several previous articles that have applied life cycle assessments (LCA) to the UWC have shown that the cycle has major environmental impacts. For instance, the construction and operation of the UWC can require the release of 0.03 to $0.279 \mathrm{t}$ of $\mathrm{CO} 2$ eq./year-inhabitant (Sharma et al., 2009; Friedrich et al., 2009) or 1.5 to $2.5 \mathrm{t}$ of $\mathrm{CO} 2$ eq./m3 (Muñoz et al., 2010). One of the most impactful elements of the UWC pertains to wastewater treatment, as shown in some previous studies focusing on this issue (Lassaux et al., 2007; Del Borghi et al., 2008; Hospido et al., 2008). Thus, a further assessment of these environmental impacts is needed to increase the completeness and accuracy of available data.

Within the UWC, water transport networks serve as a significant contributor to its environmental impacts (Sanjuan et al., 2013; Petit-Boix et al., 2014). The drinking water transport and distribution network (DWTDN) serves as the necessary infrastructure required to bring water from a drinking water tank to a consumption point and can account for between 20 and 40\% of UWC environmental effects (Amores et al., 2013; Lemos et al., 2013).

The use phase of the DWTDN is especially relevant due to the environmental impacts of energy used for water pumping (Piratla et al., 2012). However, its environmental impacts vary considerably across case studies. The amount of energy required to pump water, whose consumption can imply emissions of 5.53 $\mathrm{kg}$ of $\mathrm{CO}_{2}$ per inhabitant each year, is dependent on case-specific factors such as the topography of the area where a network is located and the position of different elements (Sanjuan-Delmás et al., 2014). Environmental impacts of the DWTDN maintenance phase are negligible in comparison with those of the construction phase (Venkatesh \& Brattebø, 2011; Piratla et al., 2012; Del Borghi et al., 2013). Given the above findings, this article focuses on the construction phase to obtain useful results that can be generalised to all networks. 
When focusing on the construction phase, most impacts occur during network expansion (while the extended network is being built) (Venkatesh \& Brattebø, 2012). A previous article by Sanjuan-Delmás et al. (2013) presents a method for calculating the environmental impacts of a small to mid-sized city DWTDN. The outputs of the present study will contribute new information on drinking water supplies, providing reliable data on the environmental impacts of water tanks.

\subsection{Drinking water tanks}

This study examines drinking water tanks, which form a basic component of the DWTDN. The configuration of water tanks within the DWTDN must ensure required water quantity, quality and pressure levels. However, few studies have analysed water tanks individually, which may present relevant effects. The outputs of this study will fill an existing gap in the environmental assessment of drinking water tanks via LCA, offering more completeness to the available data on DWTDN and UWC system emissions.

Typically, mid-sized cities (10,000 to 50,000 inhabitants) include several water tanks that perform one or more of the following functions: flow regulation, pressure regulation and supply security. Municipal water tanks that service mid-sized and large cities are typically constructed of concrete, given that this is the most common material used to construct large tanks. According to their geometries, water tanks can take various shapes. The most common are rectangular and cylindrical in geometry. Among all possible configurations, the cylindrical form serves as the best structural configuration and allows for a greater optimisation of materials, as it offers the smallest perimeter for a given height and volume (CEDEX, 2010). For this reason, the analysis performed in this paper focuses on cylindrical configurations as a first step. However, cylindrical tanks cannot always be installed due to urban form limitations. Thus, an analysis of rectangular tanks will also be of interest to the reader.

Water tanks can require the use of maintenance operations given their long lifespan. Takeuchi et al. (2004) assessed the maintenance of a highly deteriorated 4,500 $\mathrm{m}^{3}$ concrete water tank in Chiba (Japan). Repairs involved spraying anticorrosion paint on the inner surface, repairing concrete along the outer surface and replacing the dome.

Whereas several guidelines have been published on technical aspects of water tanks (EPA, 2002; AWWA, 1995; Walski, 2000; CEDEX, 2010), little research has been conducted on their environmental 
impact and sustainability. Small water tanks (up to $200 \mathrm{~m}^{3}$ ) for water storages in rainwater harvesting systems have been analysed from a LCA perspective (Angrill et al., 2011; Vargas-Parra et al., 2013). Wastewater tanks have also been environmentally assessed (Llopart-Mascaró et al., 2014) with a focus on the influence and quality of wastewater.

The goal of the present article is to optimise cylindrical water tanks from a geometric and environmental perspective. In defining environmental standards (the less impactful option for each dimension assessed: geometry, position and storage capacity), we aim to reduce environmental effects of drinking water tank construction. The specific goals of the study are:

- To select a number of representative cases of cylindrical water tanks that present realistic ranges of volumes, dimensions and positions (buried, superficial and partially buried).

- To assess the geometric and environmental optimisation of water tank cases analysed using the LCA methodology.

- To identify the best water tank (based on dimension, position and volume) among the cases studied for each volume and to define a curve for the calculation of environmental impacts of the optimal cases.

- To apply the assessment methodology to three case studies.

The results of the present study will serve as new information on the environmental impacts of geometrically optimised municipal water storage tanks and on which options are environmentally preferable.

\section{Materials and methods}

\subsection{Case study selection}

The following variables were considered to assess the geometric and environmental optimisation of cylindrical water tanks: (1) position in relation to ground level, (2) storage capacity (tank volume) and (3) dimensions (in terms of height and radius). Following CEDEX (2010), for constructive reasons, a $30 \mathrm{~cm}-$ thick wall is generally used when designing water tanks (given the minimum distance between walls needed to set the reinforcement and to cast the formworks). Therefore, a fixed logical $30 \mathrm{~cm}$-wall thickness value was used. 
Three different positions in relation to the ground level were considered: superficial (S; $0 \%$ of the tank

\begin{tabular}{|c|c|c|c|c|c|c|c|}
\hline \multirow{2}{*}{ Height (m) } & \multicolumn{7}{|c|}{ Radius (m) for a given volume } \\
\cline { 2 - 7 } & $\mathbf{1 0 0 \mathbf { ~ m } ^ { \mathbf { 3 } }}$ & $\mathbf{5 0 0} \mathbf{~ m}^{\mathbf{3}}$ & $\mathbf{1 , 0 0 0} \mathbf{~ m}^{\mathbf{3}}$ & $\mathbf{2 , 5 0 0 ~ \mathbf { ~ m } ^ { 3 }}$ & $\mathbf{5 , 0 0 0 ~ \mathbf { ~ m } ^ { \mathbf { 3 } }}$ & $\mathbf{7 , 5 0 0 ~ \mathbf { ~ m } ^ { 3 }}$ & $\mathbf{1 0 , 0 0 0} \mathbf{~ m}^{\mathbf{3}}$ \\
\hline 2.5 & 4.0 & 9.0 & 13.0 & 20.0 & 28.5 & 35.0 & 40.0 \\
3.5 & 3.3 & 7.5 & 10.5 & 16.5 & 23.5 & 28.5 & 33.0 \\
4.5 & 3.0 & 6.5 & 9.0 & 14.5 & 20.0 & 24.5 & 28.5 \\
5.5 & 2.6 & 5.7 & 8.0 & 13.0 & 18.0 & 22.0 & 25.5 \\
6.5 & 2.4 & 5.2 & 7.5 & 12.0 & 16.5 & 20.0 & 23.5 \\
7.5 & 2.2 & 4.8 & 7.0 & 11.0 & 15.5 & 18.5 & 21.5 \\
8.5 & 2.0 & 4.5 & 6.5 & 10.0 & 14.5 & 17.5 & 20.0 \\
\hline
\end{tabular}

In total, 147 different water tanks were analysed.

To distinguish between the different case studies, the following nomenclature beginning with $\mathrm{C}$ (cylindrical) was used: tank position ( $\mathrm{B}=$ buried, $\mathrm{PB}=$ partially buried, $\mathrm{S}=$ superficial), followed by tank volume (e.g., 100 for a $100 \mathrm{~m}^{3}$ tank) and tank height (e.g., 2 for $2.0 \mathrm{~m}$ plus 0.5 for construction purposes). In turn, a 6.5 m-tall, 1,000- $\mathrm{m}^{3}$ superficial cylindrical tank would be expressed as "CS10006".

The functional unit is the reference value that all cases compared must be referred to. This is a basic element of an LCA that must be properly defined. For this study, the functional unit considered is one cubic meter of water storage capacity, including the production, transport, installation and end of life of the water storage tank for 50 years. 
Because each structure analysed was composed of reinforced concrete, no differences were considered regarding the lifespan of each structure in our comparisons. However, the authors estimate a municipal water tank lifespan of approximately 50 years. This lifespan was used, for instance, in Vargas-Parras et al. (2013)

Thus, the resulting total impact of the tank was divided by its total capacity for each impact category (impact $/ \mathrm{m}^{3}$ of water stored). The final volume required for storing water will depend on different service factors such as the number of inhabitants.

Life cycle stages of the system assessed along with system boundaries and different elements considered for each stage are shown in Figure 1. Note that the operation phase has been excluded, as it varies considerably across cases, and especially due to water pumping differences (section 1). It is evident that energy and material consumption levels and emissions derived from the system were accounted for when analysing environmental impacts.

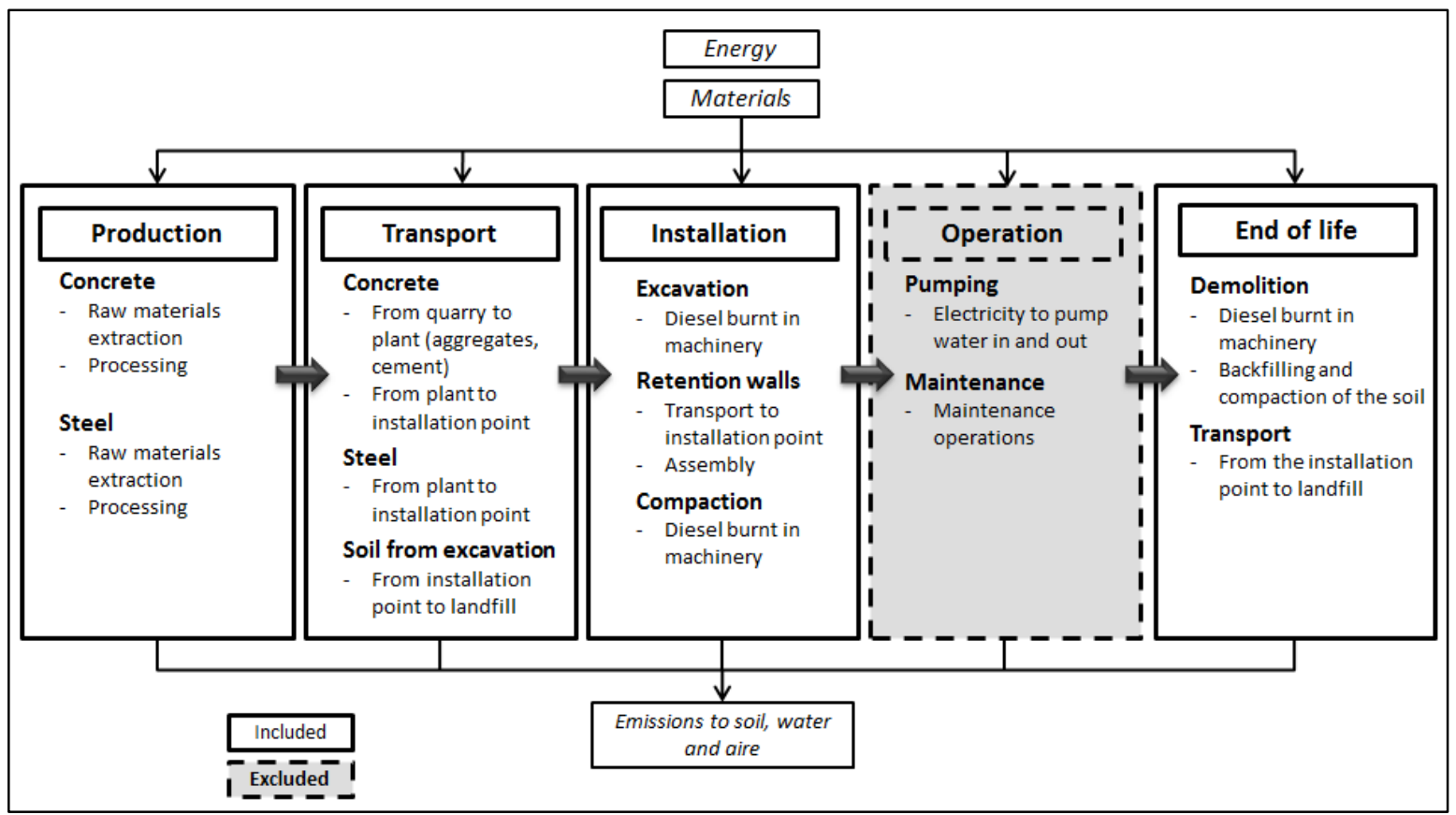

Figure 1. Diagram and system boundaries of the drinking water tank life cycle.

\subsection{Structural design performance}

The purpose of this structural study is to analyse the influence of variables examined in the parametric study (volume and position in relation to the ground and dimensions) on amounts of materials used for water tank construction. 
The volume of soil excavated and concrete and reinforcement steel required for tank construction were calculated based on tank volumes and geometric configurations. This calculation was based on the EHE design code (Spanish Ministry of Public Works, 2008), which is the Spanish regulatory framework that outlines requirements that concrete structures must meet to satisfy structural safety and security requirements. This code has already been used by other authors for cylindrical water tank design purposes (Riba et al., 2006; Orbe et al., 2013).

Figure 2 present a flowchart of the structural sectional analysis design of the EHE (Spanish Ministry of Public Works, 2008) code that was performed in this study. Tank sizes used were based on the limit state design method. Limit States are defined as cases wherein parameters are exceeded and thus wherein a given structure does not fulfil the function for which it has been designed. For the purposes of this paper, two Limit States were verified: the Ultimate Limit State (ULS, covers all Limit States giving rise to structural failure due to a loss of equilibrium, collapse or breakage thereof or in part thereof) and the Serviceability Limit State (SLS, covers all Limit States wherein required functionality, comfort or aspect requirements are not fulfilled).

It must be ensured that a structure does not exceed any of the Limit States in any of the design situations based on action design values, material characteristics and geometric data. For a certain Limit State, a checking procedure involves determining, on one hand, the effects of actions applied to the structure or in part thereof and on the other, the structure's response for the limit situation examined. The Limit State is guaranteed if it is verified, based on a sufficient reliability index, that a given structural response is no less than the effect of the applied actions. To this end, partial safety factors proposed within the EHE are considered to increase action effects while reducing the strength of each constitutive material.

Following common sector practices, $30 \mathrm{MPa}$ concrete and B500S steel materials were used in this study. Moreover, the tank was placed in a general exposure class IIB (exteriors in the absence of chlorides, subject to rainwater action, in areas with an average annual rainfall level of less than $600 \mathrm{~mm}$ ), which, according to the reference code used, generates a steel nominal coverage level of $30 \mathrm{~mm}$.

Moreover, the most unfavourable effects of actions applied to the tank were considered for design purposes (empty tanks for buried and partially buried cases, and full tanks in superficial cases). 


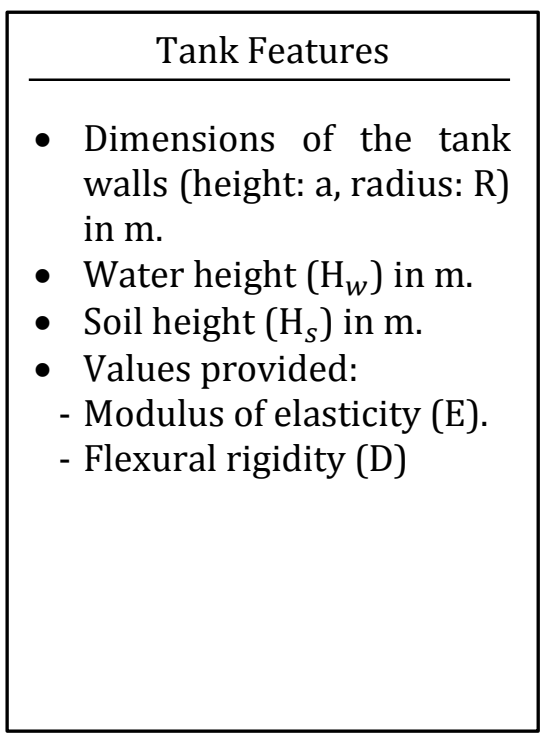

\section{Material Features: Concrete}

- Type of concrete: HA-30/P/20/IIB

- Values provided: characteristic compressive strength (fck), average tensile strength of the concrete (fctm), steel covering $\left(r_{\text {nom }}\right)$, maximum crack width $\left(w_{\max }\right)$, minimum mechanical reinforcement $\left(A s_{\min }^{m e c}\right)$, minimum mechanical reinforcement $\left(A s_{\text {min }}^{\text {geom }}\right)$.
Material Features: Steel

- Type of steel: B500S

- Values provided: yield strength (fyk), elastic modulus (Es).

- Diameter of reinforcement rebars: $\varnothing$

DETERMINING ACTIONS AND EFFORTS FOR THE TANK WALLS

\begin{tabular}{|l|}
\hline Ultimate Limit State (ULS) Verification \\
- ULS for Bending \\
- ULS for Shear Efforts \\
ULS for Axial Efforts \\
\hline
\end{tabular}

Serviceability Limit State (SLS) Verification

- SLS for cracking

\section{OUTPUTS}

Reinforcements (Steel)

- Total amount of steel required $(\mathrm{kg})$

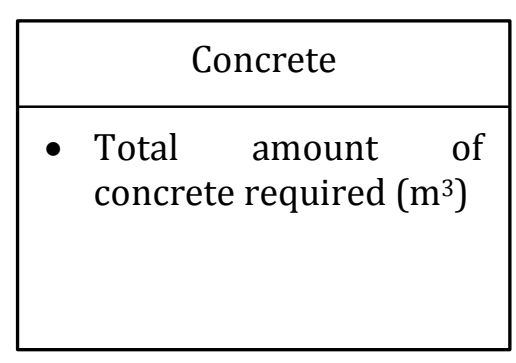

\begin{tabular}{|c|}
\hline \multicolumn{2}{|c|}{ Soil } \\
\hline - Total amount of soil \\
excavated $\left(\mathrm{m}^{3}\right)$ \\
\end{tabular}


The LCA presented in the ISO 14040 (ISO, 2006) was used for the environmental impact assessment. This method is widely accepted and used within the scientific community (Guinée et al., 2011). The process-LCA methodology was used in the study. Other LCA methods such as the economic input-output LCA and hybrid LCA allow for a broader examination of systems and account for second-order environmental impacts (Stokes and Horvath, 2011;Noori et al., 2013, 2014). However, the process-LCA was considered more appropriate for this study, as it aims to include a large number of cases (147) and because the optimisation method used is based on engineering facets, not including those of economic valuation. Moreover, the study focuses on tank construction (not on the operation phase) to considerably reduce the case study impact variations.

The Simapro 7.3 software program is used in addition to the CML 2001 V2.05 calculation method (Guinée et al., 2002). All environmental data were drawn from the Ecoinvent 2.2 database (ecoinvent, 2009), allowing us to compare the cases assessed.

The following six midpoint impact categories were considered: abiotic depletion potential (ADP), acidification potential (AP), eutrophication potential (EP), global warming potential (GWP), ozone layer depletion (ODP) and photochemical oxidation potential (POCP). Additionally, another midpoint impact category, cumulative energy demand (CED), was considered.

\subsection{Data sources}

The database compiled by the Institute of Technology of Catalonia (Metabase Itec, 2010) was used to obtain data on energy and materials consumed during water tank construction.

For the transport of materials, the following standard distances, which have already been used in previous studies (Mendoza et al., 2012; Oliver-Solà et al., 2009; Kellenberger \& Althaus, 2009), were considered. For the manufacture of reinforced concrete, $75 \mathrm{~km}$ were considered for cement from the quarry to concrete plant; this distance was designated as $40 \mathrm{~km}$ for the aggregates. For the distance from the facility to the installation site and from the site to the landfill at the end of life, a distance of $30 \mathrm{~km}$ was used.

227 From the plant to the installation site, a distance of $130 \mathrm{~km}$ was used for the reinforcement of steel bars. 

characteristics of the three case studies. These case studies were based on data on real water tanks.

230 Table 2. Technical characteristics of the water tanks analysed as case studies.

\begin{tabular}{|c|c|c|c|c|c|c|}
\hline ID & Volume ( $\left.\mathbf{m}^{3}\right)$ & Diameter (m) & Height (m) & $\begin{array}{l}\text { Wall thickness } \\
(\mathrm{cm})\end{array}$ & Shape & Material \\
\hline 1 & 400 & 5.05 & 5 & \multirow{3}{*}{30} & \multirow{3}{*}{ Cylindrical } & \multirow{3}{*}{$\begin{array}{c}\text { Reinforced } \\
\text { concrete }\end{array}$} \\
\hline 2 & 2,000 & 11 & 5.3 & & & \\
\hline 3 & 8,000 & 18.5 & 7.4 & & & \\
\hline
\end{tabular}

231

232 


\subsubsection{Geometric assessment}

236 An optimal geometric configuration is given for the solution that uses fewer materials for a given water

237 volume. The quantity of materials needed for each case is determined at the design phase. In accordance 238 with standard designs, the concrete section each configuration studied remains relatively constant. Rather, the quantity of concrete does not influence the results. Therefore, this section focuses on the amount of steel required for tank construction.

241 Figure 3 presents steel reinforcements required for the construction of water tanks for all volumes

242 analysed depending on different geometric configurations. To improve our representation of the results,

243 only superficial tanks are shown (buried and semi-buried tanks present similar patterns), and the cases

244 have been divided in two groups based on volume. However, the rest of the data can be found in 245 Supplementary table A.

246 As shown in Figure 3, taller (and shorter radius) tanks require less material for construction purposes for

247 all of the volumes studied. This is attributable to the fact that the relationship between height and radius 248 allows for superior stress distribution, reducing reinforcement requirements and therefore the quantity of 249 materials required for construction. Nevertheless, this curve has an inferior limit, after which it becomes 250 stagnant. 


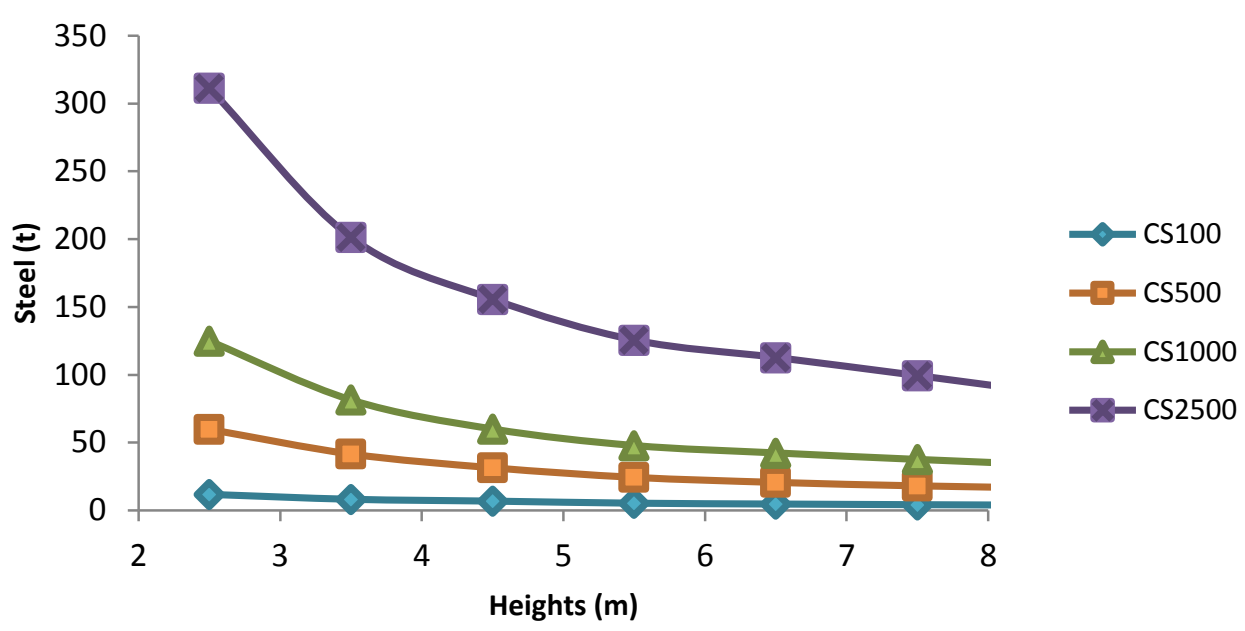

252

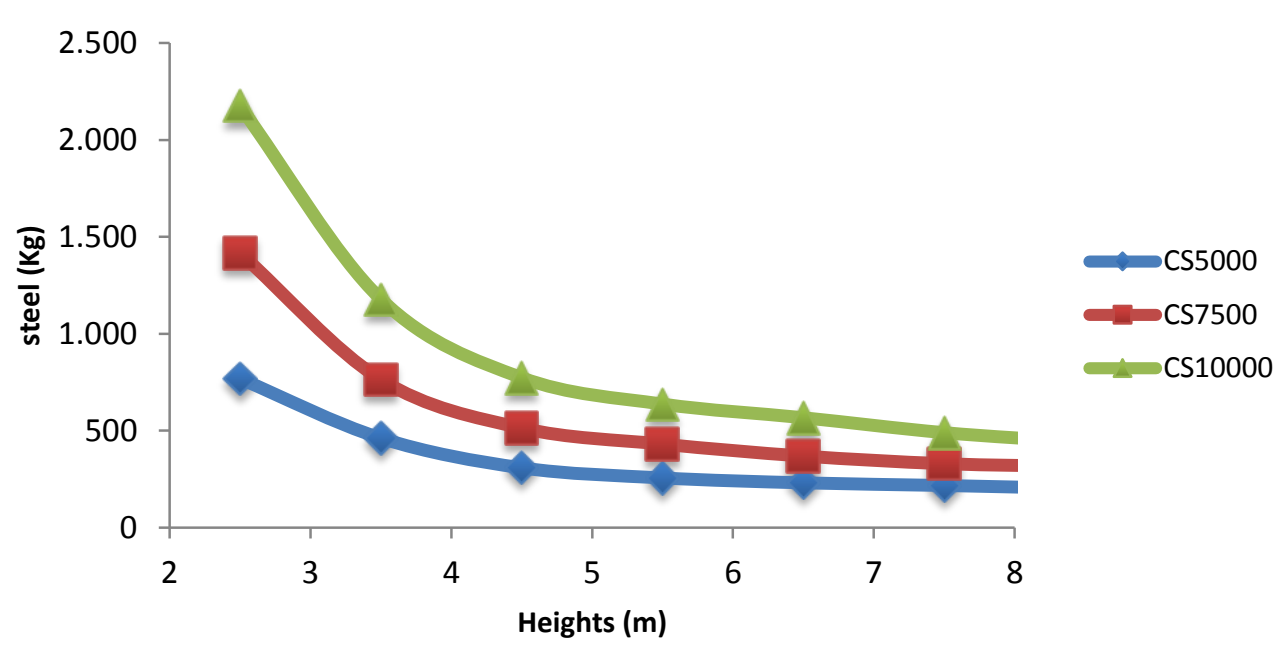

Figure 3. Total amount of reinforcing steel required for the construction of superficial water tanks with $100,500,1,000,2,500,5,000,7,500$ and $10,000 \mathrm{~m}^{3}$ of storage capacity depending on height.

256 CS= cylindrical water tanks superficially placed.

\subsubsection{Assessment of positions in relation to the ground}

The most optimal geometric configuration ( 8.5 meter tall tanks) was considered for our analysis of different tank typologies in relation to the ground (partially buried, superficial or buried).

For each cylindrical tank typology, Figure 4 presents the quantity of materials required for the construction of each volume. The chosen variables are expressed by the following ratios. (1) The materials consumption is expressed in terms of $\frac{\mathrm{kg} \text { Steel }}{\mathrm{kg} \text { Concrete }}$. As the amount of concrete remains constant for each typology, this ratio expresses the evolution of material consumption for all volumes depending on geometric configurations. (2) The geometric configuration of each volume is evaluated as $\frac{2 R}{H_{W}}$ over the 

express the results of all volumes evaluated together.

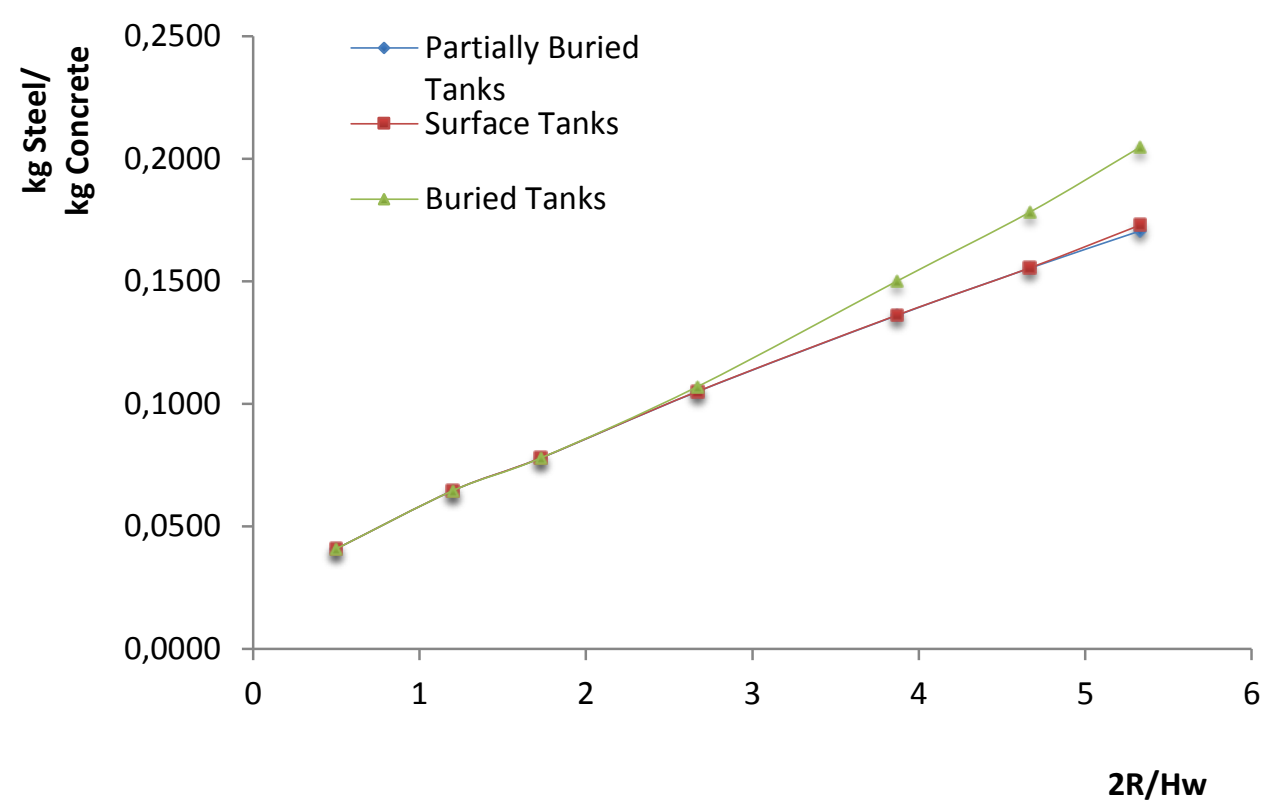

Figure 4. Materials consumption evolution for all volumes. $\mathrm{D}=$ diameter, $\mathrm{Hw}=\mathrm{Tank}$ water level

269 As shown in Figure 4, for low 2R/Hw ratios, SLS cracking criteria in the design prevail, resulting in unnoticeable differences between the three typology studies. However, as volumes evaluated increase, the buried tank typology requires more materials than the other two typologies. This is attributable to the fact that as the tank configuration levels increase, enhancement efforts increase as well, resulting in a remarkable increase in required reinforcements in the buried typology for the purposes of ULS fulfilment. Following the comparison of evolving material consumption levels shown in Figure 4, it is found that the buried tank configuration requires highest degree of material consumption.

277 Finally, the quantity of steel and concrete per $\mathrm{m}^{3}$ of storage capacity was calculated for the optimal cases 278 defined above ( $8.5 \mathrm{~m}$ tall, superficially positioned tanks) for each volume assessed. Similar results have been observed for other positions (buried, partially buried) but not for cases with different dimensions.

Figure 5 presents the quantity of concrete and steel per cubic meter of water storage capacity. It can be observed that while the relative amount of concrete is lower for larger volumes, the opposite occurs in the case of steel, whose relative quantity is higher for larger volumes. 
283

284

285

286

287

288

289

291

292

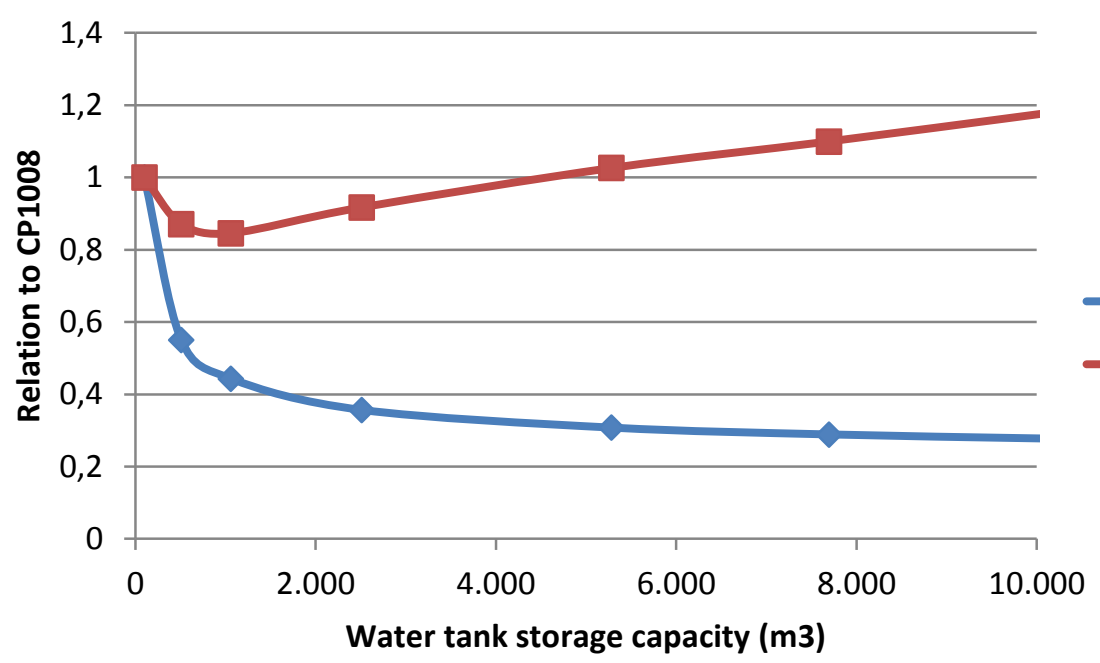

Figure 5. Comparison between quantities of concrete and steel per cubic meter of water storage capacity and the ratio between these materials for 8.5 -m-tall superficially placed water tanks.

Case nomenclature: $\mathrm{CP}=$ partially buried cylindrical water tank, $100=$ capacity $\left(\mathrm{m}^{3}\right), 8=8.5 \mathrm{~m}$ in height

Concrete per cubic meter quantities decrease sharply from 100 to $2,500 \mathrm{~m}^{3}(-65 \%)$ and slightly from 2,500 to $10,000 \mathrm{~m}^{3}(-20 \%)$. By contrast, the amount of steel decreases by $15 \%$ from 100 to $1,000 \mathrm{~m}^{3}$ and increases by nearly $30 \%$ from 1,000 to $10,000 \mathrm{~m}^{3}$. This occurs because smaller volumes only require minimal (constant) reinforcement, whereas larger ones require more reinforcement.

Thus, proportions of steel and concrete differ for different storage capacities. The environmental performance of each case thus depends on environmental impacts per unit of concrete and reinforcing steel and on the ratio of these two materials.

\subsection{Environmental assessment}

\subsubsection{Geometric configuration}

First, impacts of the different geometric configurations (different height and radius combinations; section 2.1) considered for each volume were assessed. To illustrate these results, environmental impacts of the smallest $\left(100 \mathrm{~m}^{3}\right)$ and largest $\left(10,000 \mathrm{~m}^{3}\right)$ partially buried water tanks are presented in Table 3 . The other cases (with intermediate volumes and other positions) present values that fall within the range shown in Table 3. The results for the rest of the cases can be found in Supplementary table B.

The results show that the tallest tank (CP1008) has an impact equivalent to roughly half that of the shortest (CP1002) tank for the $100 \mathrm{~m}^{3}$ water tanks and equivalent to roughly one third that of the 10,000 
$\mathrm{m}^{3}$ tanks for all of the impact categories analysed. As explained in section 3.1, these lower steel and concrete requirements for higher tanks are attributable to superior stress distribution. Thus, the results of the environmental assessment correspond with those of the structural analysis.

However, increasing tank height while reducing tank radius is only useful to a certain point.

Table 3. Comparison between the environmental impacts of 100 and $10,000 \mathrm{~m}^{3}$ water tanks for seven $\mathrm{m})$.

\begin{tabular}{|c|c|c|c|c|c|c|c|}
\multicolumn{1}{c|}{} & \multicolumn{7}{c|}{ Percentage of environmental impact } \\
\cline { 2 - 8 } \multicolumn{1}{c|}{} & CP1002 & $\mathbf{C P 1 0 0 3}$ & $\mathbf{C P 1 0 0 4}$ & $\mathbf{C P 1 0 0 5}$ & $\mathbf{C P 1 0 0 6}$ & $\mathbf{C P 1 0 0 7}$ & CP1008 \\
\hline ADP & $100 \%$ & $74 \%$ & $66 \%$ & $55 \%$ & $51 \%$ & $50 \%$ & $45 \%$ \\
\hline AP & $100 \%$ & $79 \%$ & $74 \%$ & $63 \%$ & $61 \%$ & $62 \%$ & $55 \%$ \\
\hline EP & $100 \%$ & $74 \%$ & $66 \%$ & $54 \%$ & $51 \%$ & $49 \%$ & $44 \%$ \\
\hline GWP & $100 \%$ & $78 \%$ & $73 \%$ & $63 \%$ & $61 \%$ & $63 \%$ & $56 \%$ \\
\hline ODP & $100 \%$ & $80 \%$ & $76 \%$ & $66 \%$ & $64 \%$ & $66 \%$ & $59 \%$ \\
\hline POCP & $100 \%$ & $72 \%$ & $62 \%$ & $50 \%$ & $45 \%$ & $43 \%$ & $38 \%$ \\
\hline CED & $100 \%$ & $75 \%$ & $68 \%$ & $57 \%$ & $54 \%$ & $53 \%$ & $48 \%$ \\
\hline
\end{tabular}

\begin{tabular}{|l|l|l|l|l|l|l|} 
CP100002 & CP100003 & CP100004 & CP100005 & CP100006 & CP100007 & CP100008 \\
\hline
\end{tabular}

\begin{tabular}{|c|c|c|c|c|c|c|c|}
\hline ADP & $100 \%$ & $55 \%$ & $42 \%$ & $38 \%$ & $36 \%$ & $33 \%$ & $31 \%$ \\
\hline AP & $100 \%$ & $59 \%$ & $48 \%$ & $44 \%$ & $42 \%$ & $38 \%$ & $36 \%$ \\
\hline EP & $100 \%$ & $54 \%$ & $42 \%$ & $38 \%$ & $36 \%$ & $33 \%$ & $31 \%$ \\
\hline GWP & $100 \%$ & $58 \%$ & $45 \%$ & $41 \%$ & $38 \%$ & $34 \%$ & $32 \%$ \\
\hline ODP & $100 \%$ & $61 \%$ & $49 \%$ & $45 \%$ & $43 \%$ & $40 \%$ & $37 \%$ \\
\hline POCP & $100 \%$ & $52 \%$ & $40 \%$ & $36 \%$ & $34 \%$ & $31 \%$ & $29 \%$ \\
\hline CED & $100 \%$ & $56 \%$ & $43 \%$ & $39 \%$ & $37 \%$ & $34 \%$ & $31 \%$ \\
\hline
\end{tabular}

$\mathrm{ADP}=$ Abiotic depletion potential, $\mathrm{AP}=$ Acidification potential, $\mathrm{EP}=$ Eutrophication potential,

311 GWP=Global warming potential, ODP=Ozone layer depletion potential, $\mathrm{POCP}=$ Photochemical oxidation

312 potential, $\mathrm{CED}=$ Cumulative energy demand

313 Case nomenclature: $\mathrm{CP}=$ partially buried cylindrical water tank, $100-10000=$ capacity $\left(\mathrm{m}^{3}\right), 2-8=2.5$ to 8.5

$314 m$ in height

316 As shown in the section above, only the smallest and largest of the volumes analysed are included in

317 Figure 6. Optimal dimensions (8.5 $\mathrm{m}$ in height and $40 \mathrm{~m}$ in diameter) presented in section 3.1 and 3.2.1

318 were considered for each case. Environmental impacts for the rest of the case studies analysed can be

319 found in Supplementary table B. 
320 As shown in Figure 6, superficial water tanks present the lowest environmental impacts across all impact 321 categories (between 15 and $35 \%$ less for $100 \mathrm{~m}^{3}$ water tanks and between 20 and $35 \%$ less for $10,000 \mathrm{~m}^{3}$ 322 water tanks). Superficially placed water tanks do not require soil excavation and landfill transport. For 323 this reason, superficial water tanks constitute the environmentally preferred option. These results are also 324 consistent with those presented in section 3.1, as superficial water tanks require less reinforcing steel. 325 Though not considered in this study, it may be possible to use excess soil for tank wall reinforcement 326 purposes to at least partially mitigate the impacts from the transport and landfilling of this material.

327 While there are economic incentives to position tanks on the ground surface (as such installation requires 328 less energy, materials and working hours), it must be highlighted that tank positioning cannot always be 329 chosen. In urban areas, tanks are typically buried when there are limitations pertaining to space or the price of land or for aesthetical reasons. Given this, optimal position selection (superficial) is not always possible. 


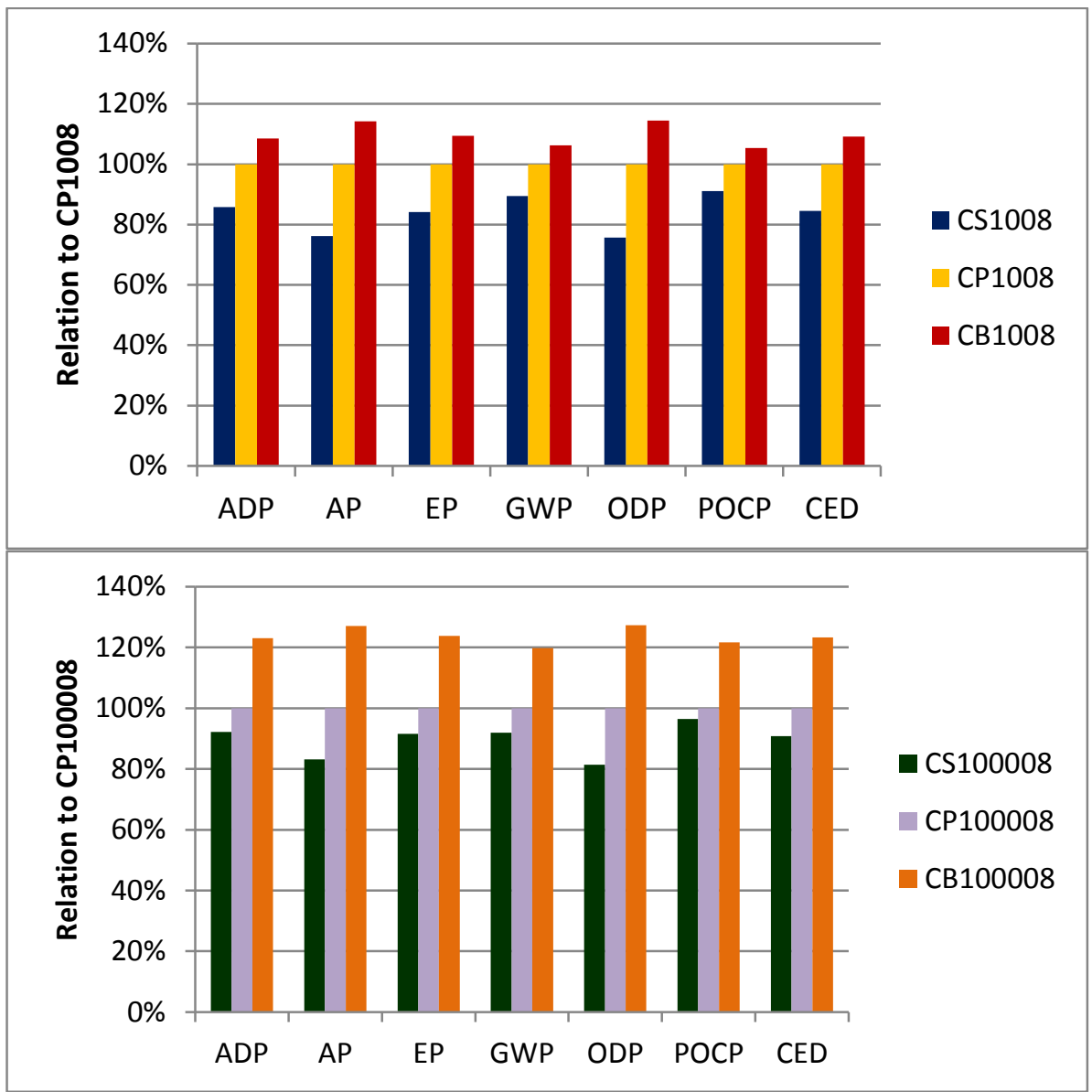

335 Figure 6. Comparison between environmental impacts of $8.5 \mathrm{~m}$ tall 100 and $10,000 \mathrm{~m}^{3}$ cylindrical water tanks that are buried, partially buried or superficially positioned. $\mathrm{ADP}=$ Abiotic depletion potential, $\mathrm{AP}=$ Acidification potential, $\mathrm{EP}=$ Eutrophication potential, $\mathrm{GWP}=$ Global warming potential, $\mathrm{ODP}=$ Ozone layer depletion potential, $\mathrm{POCP}=\mathrm{Photochemical}$ oxidation potential, $\mathrm{CED}=$ Cumulative energy demand

Case nomenclature: $\mathrm{CP}=$ partially buried cylindrical water tank, 100/10000=capacity $\left(\mathrm{m}^{3}\right), 2 / 8=2.5$ and $8.5 \mathrm{~m}$ in height

\subsubsection{Capacity optimisation}

Finally, the environmental impacts per cubic meter of storage capacity were determined for each volume for the most optimal cases shown in sections 3.2.1 and 3.2.2 (the tallest superficially placed tanks). Figure 7 shows the results, including one curve for each impact category evaluated. The absolute environmental impacts per cubic meter of stored water can be found in Supplementary table $C$. 


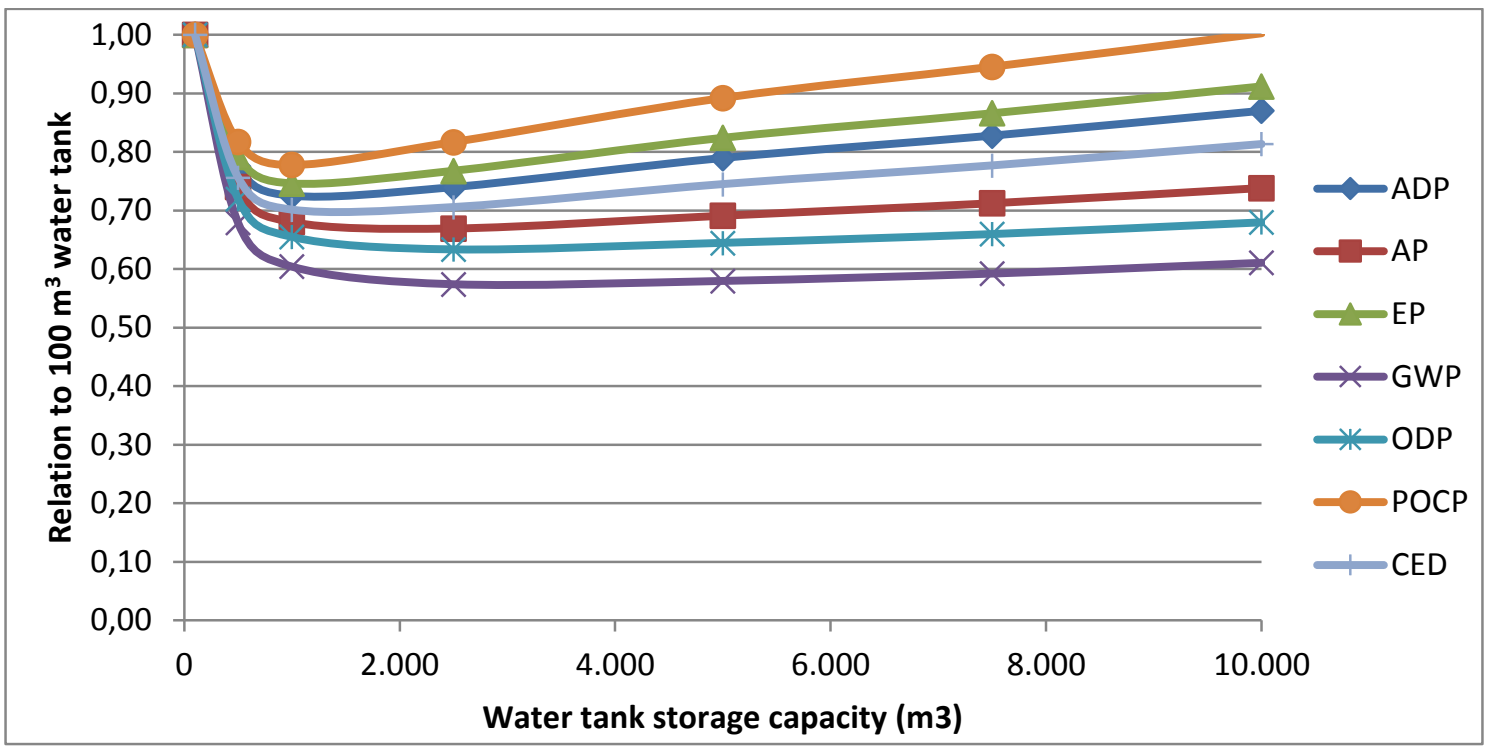

349 Figure 7. Environmental impacts per $\mathrm{m}^{3}$ of storage capacity for superficially placed water tanks of $8.5 \mathrm{~m}$

350 in height.

$351 \mathrm{ADP}=$ Abiotic depletion potential, $\mathrm{AP}=$ Acidification potential, $\mathrm{EP}=$ Eutrophication potential,

$352 \mathrm{GWP}=\mathrm{Global}$ warming potential, $\mathrm{ODP}=\mathrm{Ozone}$ layer depletion potential, $\mathrm{POCP}=\mathrm{Photochemical}$ oxidation

353 potential, $\mathrm{CED}=$ Cumulative energy demand

354 Environmental impact variations are not equal for each category. For AP, ODP and GWP, the 2,500 $\mathrm{m}^{3}$ water tank has the lowest environmental impact, with impacts being between 15 and $40 \%$ higher for tanks that are smaller than $500 \mathrm{~m}^{3}$. Nevertheless, environmental impacts increase slightly from a tank size of $1,000 \mathrm{~m}^{3}$ to $10,000 \mathrm{~m}^{3}$. This means that, in regards to greenhouse gas emissions, impacts from building one $10,000 \mathrm{~m}^{3}$ water tank versus $101,000 \mathrm{~m}^{3}$ water tanks would not differ considerably. Given these categories, decisions to select one or another should be based on other factors such as those pertaining to cost, available space or periodic maintenance and cleaning.

361 For the rest of the impact categories (CED, ADP, EP and POCP), the lowest environmental impacts correspond with the $1,000 \mathrm{~m}^{3}$ water tank, being significantly higher for volumes lower than $500 \mathrm{~m}^{3}$

363 (between 5 to $30 \%$ higher) and larger than 5,000 $\mathrm{m}^{3}$ (between 5 and $20 \%$ higher). In this case, water tanks of between 500 and $2,500 \mathrm{~m}^{3}$ show minor variations. For this reason, volumes falling within this range are environmentally preferable, with $1,000 \mathrm{~m}^{3}$ being optimal.

366 As explained in section 3.1.3, differences between impact categories are attributable to different relationships between inputs required for different volumes. It must be highlighted that the relative 
environmental impacts of steel are higher than those of concrete. This explains why the optimal volumes range from 1,000 to $2,500 \mathrm{~m}^{3}$ and why this varies depending on the impact category (due to differing proportions of these materials, which have different environmental impacts).

\subsubsection{Water tank element impacts}

Two representative impact categories are included in Figure 8 to illustrate the contribution of each life cycle element to the water tank's environmental effects (ADP and GWP). EP, ADP and CED present similar patterns of environmental impact as well as GWP, AP, EP and POCP (section 3.2.3). The water tanks represented in this section are partially buried, as the optimal (superficial) model does not require excavation and is $8.5 \mathrm{~m}$ in height. The lowest and highest volumes are also represented. The results of the rest of the cases fall within the range presented.

As shown in Figure 8, steel and concrete account for most of the water tank impacts for each option (between 70 and $80 \%$ for each case). This means that concrete and steel quantities used for water tank construction serve as the major factor determining their environmental effects, thus explaining why similar results have been obtained from the structural and environmental assessments. Thus, tank structural optimisation is crucial for the reduction of environmental impacts.

Nonetheless, material contributions vary depending on the volume and impact category. Steel contributions to environmental impacts of ADP are higher than those for GWP (approximately $50 \%$ to $75 \%$ for $\mathrm{ADP}$ as opposed to 30 to $60 \%$ for GWP). Additionally, because water tanks with larger storage capacities require more reinforcing steel, steel contributions are higher for higher volumes (nearly $60 \%$ for $10,000 \mathrm{~m}^{3}$ as opposed to $30 \%$ for $100 \mathrm{~m}^{3}$ for GWP). For POCP, steel impact percentages are higher than those of the other impact categories (between 70 and $85 \%$ for each volume), explaining differentiation shown in its curve in Figure 6.

Another significant contributor to environmental impact levels for each case pertains to material transport, representing roughly $10 \%$ of the total value. It must be highlighted that this element is highly related to the quantity of materials required for construction, reinforcing the importance of concrete and steel. 


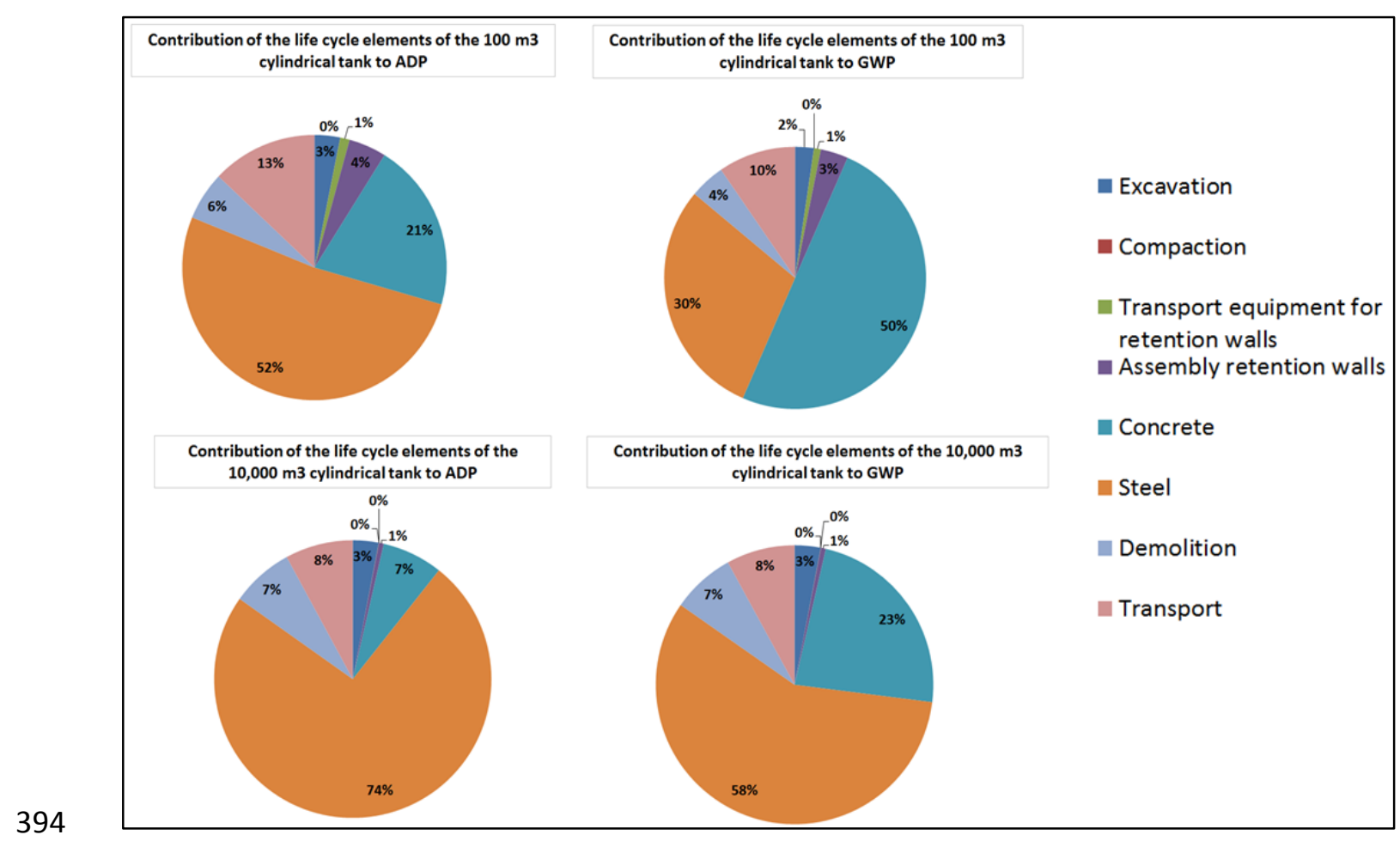

395 Figure 8. Contribution of each life cycle element to environmental impacts of ADP and GWP for 100 and $39610,000 \mathrm{~m}^{3}$ cylindrical and partially buried water tanks of $8.5 \mathrm{~m}$ in height.

$397 \mathrm{ADP}=$ Abiotic depletion potential, GWP=Global warming potential

398 Similar results were found in the case of superficial and buried water tanks. The superficial water tanks 399 had no impact in regards to the excavation and transport of extracted soil, whereas the buried tanks had greater environmental impacts. Apart from this, environmental impacts of the different elements follow a similar pattern in the other cases (Supplementary table D).

\subsubsection{Environmental assessment of case studies}

403 The results of three case study assessment are presented in Figure 9. The environmental impacts of the optimal water tank are significantly lower (between 10 and 40\%) for all of the cases. Additionally, environmental impact reduction levels are similar for all of the impact categories. Optimised water tanks 1 and 2, which are smaller in capacity (400 and 2,000 $\mathrm{m}^{3}$ ), present relatively lower levels of environmental improvement in relation to those of water tank $3\left(4,000 \mathrm{~m}^{3}\right)$. The absolute environmental impacts obtained are presented in Supplementary table E. 


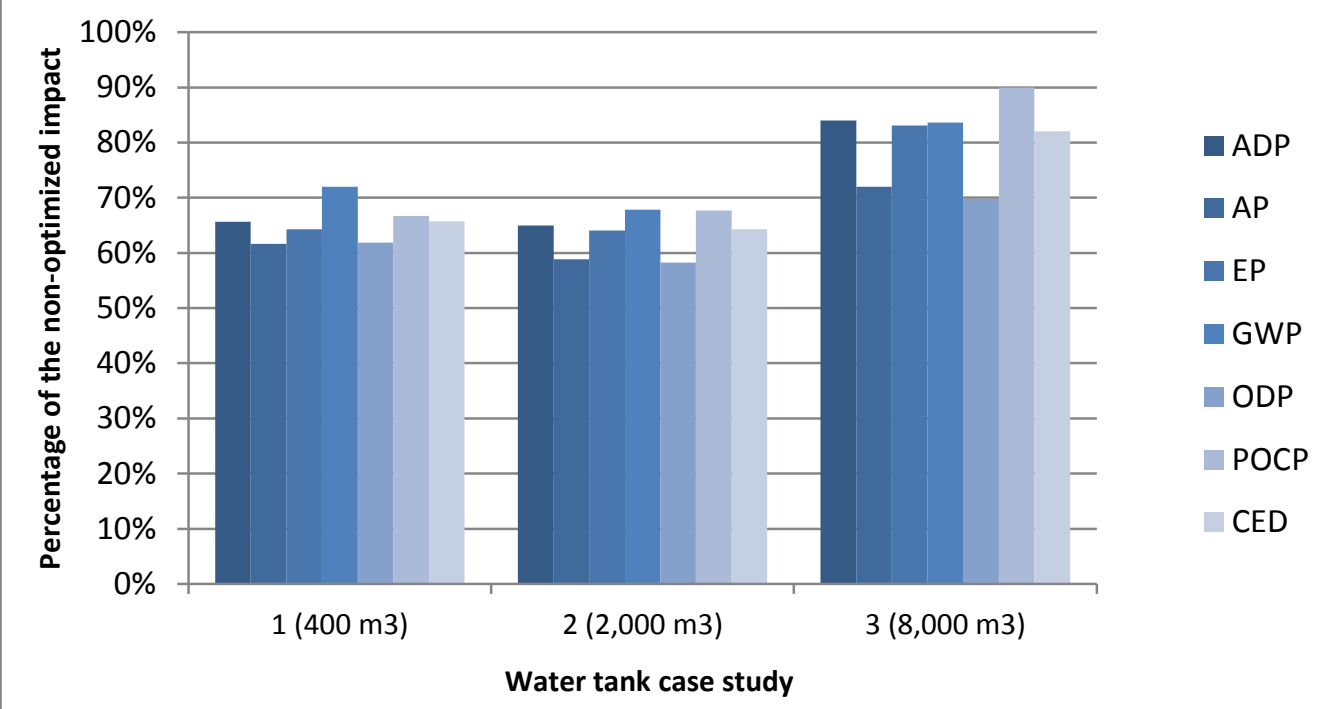

411 Figure 9. Estimation of the environmental impacts of three real drinking water tanks based on current

412 conditions and a hypothetical optimal water tank of the same volume.

$413 \mathrm{ADP}=$ Abiotic depletion potential, $\mathrm{AP}=$ Acidification potential, $\mathrm{EP}=$ Eutrophication potential,

$414 \mathrm{GWP}=\mathrm{Global}$ warming potential, $\mathrm{ODP}=\mathrm{Ozone}$ layer depletion potential, $\mathrm{POCP}=\mathrm{Photochemical}$ oxidation potential, $\mathrm{CED}=$ Cumulative energy demand

416 For water tanks 1 and 2, environmental impact reductions are attributable to lower quantities of 417 reinforcing steel required for their construction (roughly 30\% less impact). By contrast, an environmental impact reduction of only approximately $5 \%$ is found in the case of concrete material use. For water tank

4193 , these environmental savings are less significant, all falling below a 5\% reduction. For the three cases, processes of excavation were disregarded (along with their environmental impacts), as the optimal water tank found in the sample assessed is superficially positioned.

In absolute terms, the optimisation of these water tanks would reduce emissions by between 19.2 (for the $400 \mathrm{~m}^{3}$ water tank) and $170.5 \mathrm{t}$ of $\mathrm{CO}_{2}$ equivalents (for the $8,000 \mathrm{~m}^{3}$ water tank).

While these environmental savings cannot be applied to existing water tanks, applying environmental standards discussed in this article would allow for significant reductions in the environmental impacts of new municipal water tanks. 
430

After analysing a sample of 147 cases, it is concluded that the superficially placed, 8.5 meter tall water tank (and its corresponding radius according to volume) with a storage capacity of between 1,000 and $2,500 \mathrm{~m}^{3}$ performs the best environmentally.

It is environmentally preferable to position water tanks superficially rather than underground, as less reinforcing steel is required, reducing environmental burdens involved for steel manufacturing. Moreover, no excavation or soil transport tasks are required, resulting in significant energy savings. However, superficial tank installation is not always possible, as this depends on the presence of specific conditions at the installation point (e.g., urban form).

For the set of water tanks studied in this paper (each with a constant wall thickness of $30 \mathrm{~cm}$ ), the tallest (8.5 meters in height) and smallest-diameter tanks were deemed optimal from a geometric and environmental perspective. These dimensions imply a more optimised geometry and a limited use of steel.

Water tank structural optimisation is essential provided that reinforcing steel and concrete required for construction are the elements that contribute the most to tank environmental impacts (between 30 and $75 \%$ of the global impact for steel and between 7 and $50 \%$ for the global impact of concrete).

Regarding water storage capacities, water tanks with volumes ranging between 1,000 and 2,500 $\mathrm{m}^{3}$ are environmentally preferable, as the relative quantity of steel and concrete required for tank construction varies with volume. Steel and concrete have different environmental impacts, and the ratio between one and the other also varies with volume. Water tanks of $1,000 \mathrm{~m}^{3}$ serve as the best option considering GWP, ODP and AP (up to $40 \%$ lower environmental impact) impact categories, whereas $2,500 \mathrm{~m}^{3}$ water tanks are preferable considering ADP, EP, POCP and CED (up to 30\% lower impact). These results are a consequence of the relationship between steel and concrete and of their impacts, as shown in the structural analysis.

The application, when possible, of environmental standards (the less impactful option for each dimension assessed in this study: geometry, position and storage capacity) presented throughout this article is of interest to reduce impacts of new water tanks during construction. Following such standards can result in savings of between 10 and $40 \%$ of environmental impacts, as observed in our three case studies. 
457 Further studies may focus in other water tank shapes, such as rectangular tanks, which are commonly 458 used. While cylindrical water tanks present lower requirements in terms of materials and thus have fewer 459 environmental impacts (section 1), rectangular water tank construction may be required due to urban form 460 limitations. Thus, an environmental assessment of this tank configuration would be of interest.

461 5. Acknowledgements

462 The authors are also grateful to the Government of Catalonia for awarding a research scholarship (FI463 DGR 2014) to David Sanjuan Delmás and for its economic support of the research team (2014 SGR 464 1412).

465 The authors are grateful for support provided by the Spanish Ministry of Education and Science through 466 the BIA project (2010-20789-C04-01). 
468 Abiotic depletion potential (ADP)

469 Acidification potential (AP)

470 Average tensile strength of the concrete (fctm)

471 Buried (B)

472 Centro de Estudios y Experimentación de Obras Públicas (CEDEX)

473 Compressive strength (fck)

474 Cumulative energy demand (CED)

475 Cylindrical (C)

476 Drinking water transport and distribution network (DWTDN)

477 Elastic modulus (Es)

478 Eutrophication potential (EP)

479 Flexural rigidity (D)

480 Global warming potential (GWP)

481 Height (a)

482 International Standard Association (ISO)

483 Life cycle assessment (LCA)

484 Maximum crack width $\left(w_{\max }\right)$

485 Minimum geometric reinforcement amount $\left(A s_{\text {min }}^{\text {geom }}\right)$

486 Minimum mechanical reinforcement amount $\left(A s_{\min }^{\text {mec }}\right)$

487 Modulus of elasticity (E)

488 Ozone layer depletion (ODP)

489 Partially buried (PB)

490 Photochemical oxidation potential (POCPPOCP)

491 Radius (R)

492 Serviceability Limit State (SLS)

493 Soil height (Hs)

494 Steel covering $\left(r_{\text {nom }}\right)$

495 Superficial (S)

496 Ultimate Limit State (ULS)

497 United Nations Educational, Scientific and Cultural Organization (UNESCO)

498 Urban water cycle (UWC)

499 US Environmental Protection Agency's (EPA)

500 Water height (Hw)

501 Yield strength (fyk) 
- Supplementary table A - Quantity of concrete and reinforcing steel required for the construction of each case examined.

- Supplementary table B - Absolute environmental impacts of the construction of storage water tanks assessed.

- Supplementary table $C$ - Absolute environmental impacts per cubic meter of water stored for superficial cylindrical tanks of $8.5 \mathrm{~m}$ in height.

- Supplementary table D - Environmental impacts of the life cycle elements of cylindrical water tanks of $8.5 \mathrm{~m}$ in height and of 100 and $10,000 \mathrm{~m} 3$ in capacity for superficial, buried and partially buried positions. conditions and using defined environmental standards. 
Agbar @. <http://www.agbar.es/en/home.html> [Accessed on September 2013]

517

518

519

520

Aimar Orbe, M. "Optimización del uso de Hormigones Autocompactantes Reforzados con Fibras de Acero en Aplicaciones Convencionales de Resistencias Moderadas”. Tesis Doctoral. Universidad del País Vasco, 2013.

Amores, M. J., Meneses, M., Pasqualino, J., Antón, A., \& Castells, F. (2013). Environmental assessment of urban water cycle on Mediterranean conditions by LCA approach. J CLEAN PROD, 43, 8492. doi:10.1016/j.jclepro.2012.12.033

Angrill, S., Farreny, R., Gasol, C. M., Gabarrell, X., Viñolas, B., Josa, A., \& Rieradevall, J. (2011). Environmental analysis of rainwater harvesting infrastructures in diffuse and compact urban models of Mediterranean climate. INT J LIFE CYCLE ASS, 17(1), 25-42. doi:10.1007/s11367011-0330-6

AWWA (American Water Works Association). 1995c. Modeling, Analysis, and Design of Water Distribution Systems. Denver, Colo: AWWA.

CEDEX, Centro de Estudios Hidrográficos, 2009. Guía Técnica sobre tuberías para el transporte de agua a presión, sixth ed., ISBN 978-84-7790-492-2

CPH. Instrucción del Hormigón Estructural EHE-08. Madrid: Ministerio de Fomento; 2008.

Del Borghi, A., Gaggero, P. L., Gallo, M., \& Strazza, C. (2008). Development of PCR for WWTP based on a case study. The International Journal of Life Cycle Assessment, 13(6), 512-521.

Del Borghi, A., Strazza, C., Gallo, M., Messineo, S., \& Naso, M. (2013). Water supply and sustainability: life cycle assessment of water collection, treatment and distribution service. INT J LIFE CYCLE ASS, 18(5), 1158-1168. doi:10.1007/s11367-013-0549-5

ecoinvent (2009) Swiss Centre for Life Cycle Inventories. Ecoinvent database v3.0. Technical report. http://www.ecoinvent.ch/ Accessed June 2014.

Environmental Protection Agency (EPA). (2002). Finished Water Storage Facilities. PDF Document retrieved from 

er_tcr_storage.pdf

Friedrich, E., Pillay, S., \& Buckley, C. a. (2009). Carbon footprint analysis for increasing water supply and sanitation in South Africa: a case study. J CLEAN PROD, 17(1), 1-12. doi:10.1016/j.jclepro.2008.03.004

Guinée, J.B.; Gorrée, M.; Heijungs, R.; Huppes, G.; Kleijn, R.; Koning, A. de; Oers, L. van; Wegener Sleeswijk, A.; Suh, S.; Udo de Haes, H.A.; Bruijn, H. de; Duin, R. van; Huijbregts, M.A.J.

Guinée, J. B., Heijungs, R., Huppes, G., Zamagni, A., Masoni, P., Buonamici, R., Ekvall, T., Rydberg, T. (2011). Life cycle assessment: past, present, and future. Environmental Science \& Technology, 45(1), 90-6. http://doi.org/10.1021/es101316v

557

ISO 14040:2006 Environmental management -- Life cycle assessment -- Principles and framework

Kellenberger, D., \& Althaus, H. J. (2009). Relevance of simplifications in LCA of building components. BUILD ENVIRON, 44(4), 818-825.

Lassaux, S., Renzoni, R., \& Germain, A. (2007). Life Cycle Assessment of Water: From the pumping station to the wastewater treatment plant $(9 \mathrm{pp})$. The International Journal of Life Cycle

Lemos, D., Dias, A. C., Gabarrell, X., \& Arroja, L. (2013). Environmental assessment of an urban water system. J CLEAN PROD. doi:10.1016/j.jclepro.2013.04.029 J., del Río, H. \& Paraira, M. (2014). Storm tank against combined sewer overflow: Operation strategies to minimise discharges impact to receiving waters. URBAN WATER J, 1-10. 
Mendoza, J.-M. F., Oliver-Solà, J., Gabarrell, X., Rieradevall, J., \& Josa, A. (2012). Planning strategies for promoting environmentally suitable pedestrian pavements in cities. TRANSPORT RES DTR E, 17(6), 442-450. doi:10.1016/j.trd.2012.05.008

Metabase Itec, 2010. Online ITeC Database: Prices, Technical Details, Companies, Certificates, Product Pictures and Environmental Data. Retrieved from: http://www.itec.cat/metabase (accessed June 2014).

Muñoz, I., Milà-i-Canals, L., \& Fernández-Alba, A. R. (2010). Life Cycle Assessment of Water Supply Plans in Mediterranean Spain. J IND ECOL, 14(6), 902-918. doi:10.1111/j.15309290.2010.00271.x

Noori, M., Kucukvar, M., \& Tatari, O. (2013). A macro-level decision analysis of wind power as a solution for sustainable energy in the USA. International Journal of Sustainable Energy, 34(10), 629-644. http://doi.org/10.1080/14786451.2013.854796

Noori, M., Kucukvar, M., \& Tatari, O. (2014). Economic Input-Output Based Sustainability Analysis of Onshore and Offshore Wind Energy Systems. International Journal of Green Energy, 12(9), 939948. http://doi.org/10.1080/15435075.2014.890103

Oliver-Solà, J., Josa, A., Rieradevall, J., \& Gabarrell, X. (2009). Environmental optimization of concrete sidewalks in urban areas. INT J LIFE CYCLE ASS, 14(4), 302-312. doi:10.1007/s11367-0090083-7

Petit-Boix, A., Sanjuan-Delmás, D., Gasol, C. M., Villalba, G., Suárez-Ojeda, M. E., Gabarrell, X., Josa, A. \& Rieradevall, J. (2014). Environmental Assessment of Sewer Construction in Small to Medium Mid-sizedSized Cities Using Life Cycle Assessment. WATER RESOUR MANAG, 28(4), 979-997.

Piratla, K. R., Asce, S. M., Ariaratnam, S. T., Asce, M., \& Cohen, A. (2012). Estimation of CO 2 Emissions from the Life Cycle of a Potable Water Pipeline Project, (January), 22-30. doi:10.1061/(ASCE)ME.1943-5479.0000069.

Riba Genescà, E. “Cálculo y elección óptima de un depósito de agua”. Director: Antonio Aguado. Universitat Politècnica de Catalunya. Departament de Resistència de Materials i Estructures a l'Enginyeria, Barcelona, 2006. 
Sanjuan-Delmás, D., Petit-Boix, A., Gasol, C. M., Farreny, R., Villalba, G., Suárez-Ojeda, M. E., Gabarrell, X., Josa, A., Rieradevall, J. (2014). Environmental assessment of drinking water transport and distribution network use phase for small to medium-sized municipalities in Spain. J CLEAN PROD.

Sanjuan-Delmás, D., Petit-Boix, A., Gasol, C. M., Villalba, G., Suárez-Ojeda, M. E., Gabarrell, X., Josa, A., Rieradevall, J. (2013). Environmental assessment of different pipelines for drinking water transport and distribution network in small to medium cities: a case from Betanzos, Spain. J CLEAN PROD, 66, 588-598. doi:10.1016/j.jclepro.2013.10.055

Sharma, A. K., Grant, A. L., Grant, T., Pamminger, F., \& Opray, L. (2009). Environmental and Economic Assessment of Urban Water Services for a Greenfield Development. ENVIRON ENG SCI, 26(5), 921-934. doi:10.1089/ees.2008.0063

Spanish Ministry of Public Works. (2008). EHE-08 Instrucción de Hormigón Estructural. ISBN: 978-84498-0899-9

Stokes, J., \& Horvath, A. (2011). Life-Cycle Assessment of Urban Water Provision: Tool and Case Study in California. Journal of Infrastructure Systems, 17(1), 15-24. http://doi.org/10.1061/(ASCE)IS.1943-555X.0000036

Takeuchi, H., Asce, M., Taketomi, S., Samukawa, S., Nanni, A., \& Asce, F. (2004). Renovation of Concrete Water Tank in Chiba Prefecture, Japan. Practice Periodical on Structural Design and Construction, American Society of Civil Engineers library. (November 2004), 237-241.

United Nations Educational, Scientific, and Cultural Organization (UNESCO). (2012). Managing water under uncertainty and risk. In: The United Nations World Water Development Report 4, vol. 1. PDF document retrieved from: http://www.unesco.org/new/en/naturalsciences/environment/water/wwap/wwdr/wwdr4-2012/\#c219661

Venkatesh, G., \& Brattebø, H. (2011). Energy consumption, costs and environmental impacts for urban water cycle services: Case study of Oslo (Norway). ENERGY, 36(2), 792-800. doi:10.1016/j.energy.2010.12.040 
622 Venkatesh, G., \& Brattebø, H. (2012). Assessment of Environmental Impacts of an Aging and Stagnating Water Supply Pipeline Network. J IND ECOL, 16(5), 722-734. doi:10.1111/j.15309290.2011.00426.x

625

626

627

628

629
Vargas-Parra, M. V., Villalba, G., \& Gabarrell, X. (2013). Applying exergy analysis to rainwater harvesting systems to assess resource efficiency. RESOUR CONSERV RECY, 72, 50-59.

Walski, T.M. 2000. "Hydraulic Design of Water Distribution Storage Tanks”. Chapter 10 in Water Distribution Systems Handbook, Edited by L.W. Mays, New York. NY: McGraw-Hill. 
Table 1. Case study dimensions.

\begin{tabular}{|c|c|c|c|c|c|c|c|}
\hline \multirow{2}{*}{ Height (m) } & \multicolumn{7}{|c|}{ Radius (m) for a given volume } \\
\cline { 2 - 8 } & $\mathbf{1 0 0 \mathbf { ~ m } ^ { \mathbf { 3 } }}$ & $\mathbf{5 0 0} \mathbf{~ m}^{\mathbf{3}}$ & $\mathbf{1 , 0 0 0} \mathbf{~ m}^{\mathbf{3}}$ & $\mathbf{2 , 5 0 0} \mathbf{~}^{\mathbf{3}}$ & $\mathbf{5 , 0 0 0} \mathbf{~}^{\mathbf{3}}$ & $\mathbf{7 , 5 0 0} \mathbf{~ m}^{\mathbf{3}}$ & $\mathbf{1 0 , 0 0 0} \mathbf{~}^{\mathbf{3}}$ \\
\hline 2.5 & 4.0 & 9.0 & 13.0 & 20.0 & 28.5 & 35.0 & 40.0 \\
3.5 & 3.3 & 7.5 & 10.5 & 16.5 & 23.5 & 28.5 & 33.0 \\
4.5 & 3.0 & 6.5 & 9.0 & 14.5 & 20.0 & 24.5 & 28.5 \\
5.5 & 2.6 & 5.7 & 8.0 & 13.0 & 18.0 & 22.0 & 25.5 \\
6.5 & 2.4 & 5.2 & 7.5 & 12.0 & 16.5 & 20.0 & 23.5 \\
7.5 & 2.2 & 4.8 & 7.0 & 11.0 & 15.5 & 18.5 & 21.5 \\
8.5 & 2.0 & 4.5 & 6.5 & 10.0 & 14.5 & 17.5 & 20.0 \\
\hline
\end{tabular}

633

634 Table 2. Technical characteristics of the water tanks analysed as case studies.

\begin{tabular}{|c|c|c|c|c|c|c|} 
ID & Volume $\left(\mathbf{m}^{\mathbf{3}}\right)$ & Diameter $(\mathbf{m})$ & Height $(\mathbf{m})$ & $\begin{array}{c}\text { Wall thickness } \\
(\mathbf{c m})\end{array}$ & Shape & Material \\
\hline 1 & 400 & 5.05 & 5 & 30 & Cylindrical & $\begin{array}{c}\text { Reinforced } \\
\text { concrete }\end{array}$ \\
\hline 2 & 2,000 & 11 & 5.3 & & \\
\hline 3 & 8,000 & 18.5 & 7.4 & & \\
\hline
\end{tabular}

635

636

637

Table 3. Comparison between environmental impacts of 100 and $10,000 \mathrm{~m}^{3}$ water tanks of seven different geometric configurations (height and radius); percentages are related to the lowest height $(2.5 \mathrm{~m})$.

\begin{tabular}{|c|c|c|c|c|c|c|c|}
\cline { 2 - 8 } \multicolumn{1}{c|}{} & \multicolumn{7}{c|}{ Percentage of environmental impact } \\
\hline & CP1002 & CP1003 & CP1004 & CP1005 & CP1006 & CP1007 & CP1008 \\
\hline ADP & $100 \%$ & $74 \%$ & $66 \%$ & $55 \%$ & $51 \%$ & $50 \%$ & $45 \%$ \\
\hline AP & $100 \%$ & $79 \%$ & $74 \%$ & $63 \%$ & $61 \%$ & $62 \%$ & $55 \%$ \\
\hline EP & $100 \%$ & $74 \%$ & $66 \%$ & $54 \%$ & $51 \%$ & $49 \%$ & $44 \%$ \\
\hline GWP & $100 \%$ & $78 \%$ & $73 \%$ & $63 \%$ & $61 \%$ & $63 \%$ & $56 \%$ \\
\hline ODP & $100 \%$ & $80 \%$ & $76 \%$ & $66 \%$ & $64 \%$ & $66 \%$ & $59 \%$ \\
\hline POCP & $100 \%$ & $72 \%$ & $62 \%$ & $50 \%$ & $45 \%$ & $43 \%$ & $38 \%$ \\
\hline CED & $100 \%$ & $75 \%$ & $68 \%$ & $57 \%$ & $54 \%$ & $53 \%$ & $48 \%$ \\
\hline
\end{tabular}

\begin{tabular}{|c|c|c|c|c|c|c|c|}
\hline \multicolumn{1}{c|}{} & $\mathbf{C P 1 0 0 0 0 2}$ & $\mathbf{C P 1 0 0 0 0 3}$ & $\mathbf{C P 1 0 0 0 0 4}$ & $\mathbf{C P 1 0 0 0 0 5}$ & $\mathbf{C P 1 0 0 0 0 6}$ & $\mathbf{C P 1 0 0 0 0 7}$ & $\mathbf{C P 1 0 0 0 0 8}$ \\
\hline ADP & $100 \%$ & $55 \%$ & $42 \%$ & $38 \%$ & $36 \%$ & $33 \%$ & $31 \%$ \\
\hline AP & $100 \%$ & $59 \%$ & $48 \%$ & $44 \%$ & $42 \%$ & $38 \%$ & $36 \%$ \\
\hline EP & $100 \%$ & $54 \%$ & $42 \%$ & $38 \%$ & $36 \%$ & $33 \%$ & $31 \%$ \\
\hline GWP & $100 \%$ & $58 \%$ & $45 \%$ & $41 \%$ & $38 \%$ & $34 \%$ & $32 \%$ \\
\hline ODP & $100 \%$ & $61 \%$ & $49 \%$ & $45 \%$ & $43 \%$ & $40 \%$ & $37 \%$ \\
\hline POCP & $100 \%$ & $52 \%$ & $40 \%$ & $36 \%$ & $34 \%$ & $31 \%$ & $29 \%$ \\
\hline CED & $100 \%$ & $56 \%$ & $43 \%$ & $39 \%$ & $37 \%$ & $34 \%$ & $31 \%$ \\
\hline
\end{tabular}




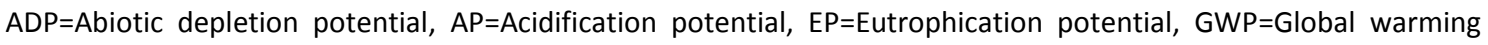
potential, $\mathrm{ODP}=\mathrm{Ozone}$ layer depletion potential, $\mathrm{POCP}=\mathrm{Photochemical}$ oxidation potential, $\mathrm{CED}=\mathrm{Cumulative}$ energy demand

641 Case nomenclature: $\mathrm{CP}=$ partially buried cylindrical water tank, $100-10000=$ capacity $\left(\mathrm{m}^{3}\right), 2-8=2.5$ to $8.5 \mathrm{~m}$ in height 
643 Figure 1. Diagram and system boundaries of the drinking water tank life cycle.

644 Figure 2. General structural design performance flowchart.

645 Figure 3. Total amount of reinforcing steel required for the construction of superficial

646 water tanks with 100, 500,1,000,2,500,5,000, 7,500 and 10,000 m3 of storage

647 capacity depending on their height.

648 Figure 4. Material consumption evolution for all volumes. $\mathrm{D}=$ diameter, $\mathrm{Hw}=\mathrm{Tank}$ water 649 level.

650

651 Figure 5. Comparison between concrete and steel quantities per cubic meter of water 652 storage capacity and the ratio between these materials for $8.5 \mathrm{~m}$ tall superficially 653 placed water tanks.

654

Figure 6. Comparison between environmental impacts of $8.5 \mathrm{~m}$ tall 100 and $10,000 \mathrm{~m} 3$

656

657

658

659

660

661

662

663 cylindrical water tanks that are buried, partially buried or superficial.

Figure 7. Environmental impacts per $\mathrm{m} 3$ of storage capacity for $8.5 \mathrm{~m}$ tall superficially placed water tanks.

Figure 8. The contribution of each life cycle element to environmental impacts of ADP and GWP for $8.5 \mathrm{~m}$ tall 100 and $10,000 \mathrm{~m} 3$ cylindrical and partially buried water tanks.

665

Figure 9. Estimation of environmental effects of three real drinking water tanks based on the present situation and a hypothetical optimal water tank of the same volume.

666 


\begin{tabular}{|c|c|c|c|c|}
\hline \multirow[b]{3}{*}{$\downarrow$} & \multirow[b]{3}{*}{$\downarrow$} & Energy & \multirow{3}{*}{\multicolumn{2}{|c|}{ v }} \\
\hline & & Materials & & \\
\hline & & $v$ & & \\
\hline Production & Transport & Installation & Operation & End of life \\
\hline $\begin{array}{l}\text { Concrete } \\
-\quad \text { Raw materials } \\
\text { extraction } \\
\text { - Processing } \\
\text { Steel } \\
-\quad \text { Raw materials } \\
\text { extraction } \\
\text { - Processing }\end{array}$ & $\begin{array}{l}\text { Steel } \\
-\quad \text { From plant to } \\
\text { installation point } \\
\text { Soil from excavation } \\
\text { - From installation } \\
\text { point to landfill }\end{array}$ & $\begin{array}{l}\text { Excavation } \\
-\quad \text { Diesel burnt in } \\
\text { machinery } \\
\text { Retention walls } \\
-\quad \text { Transport to } \\
\text { installation point } \\
- \text { Assembly } \\
\text { Compaction } \\
-\quad \text { Diesel burnt in } \\
\text { machinery }\end{array}$ & 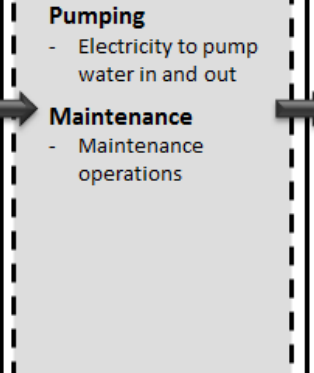 & $\begin{array}{l}\text { Demolition } \\
-\quad \text { Diesel burnt in } \\
\text { machinery } \\
- \text { Backfilling and } \\
\text { compaction of the soil } \\
\text { Transport } \\
-\quad \text { From the installation } \\
\text { point to landfill }\end{array}$ \\
\hline \multirow{2}{*}{\multicolumn{2}{|c|}{ Included }} & & & \\
\hline & & $\begin{array}{l}\text { Emissions to soil, water } \\
\text { and aire }\end{array}$ & & \\
\hline & & & & \\
\hline
\end{tabular}




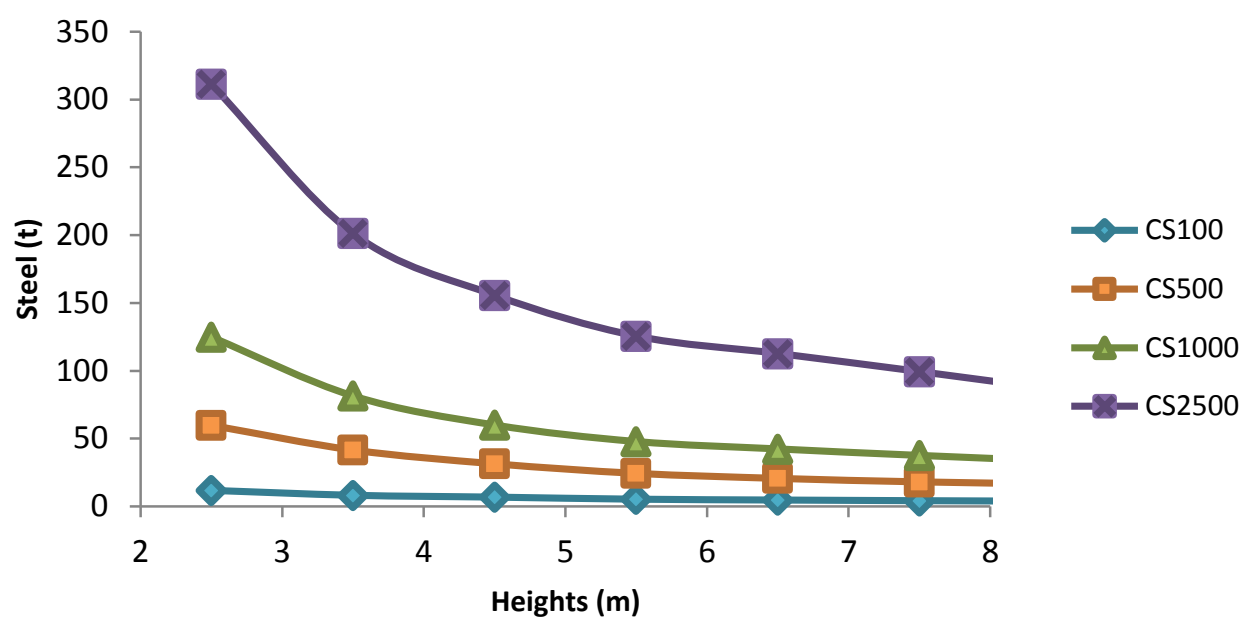

672

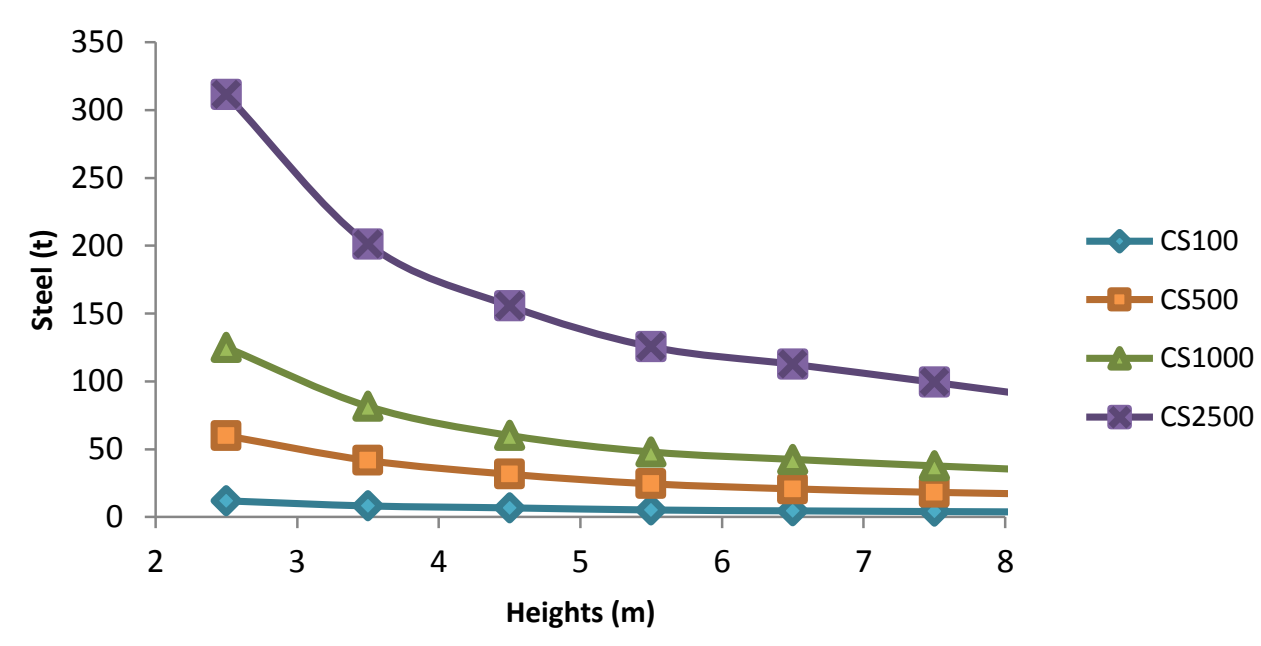




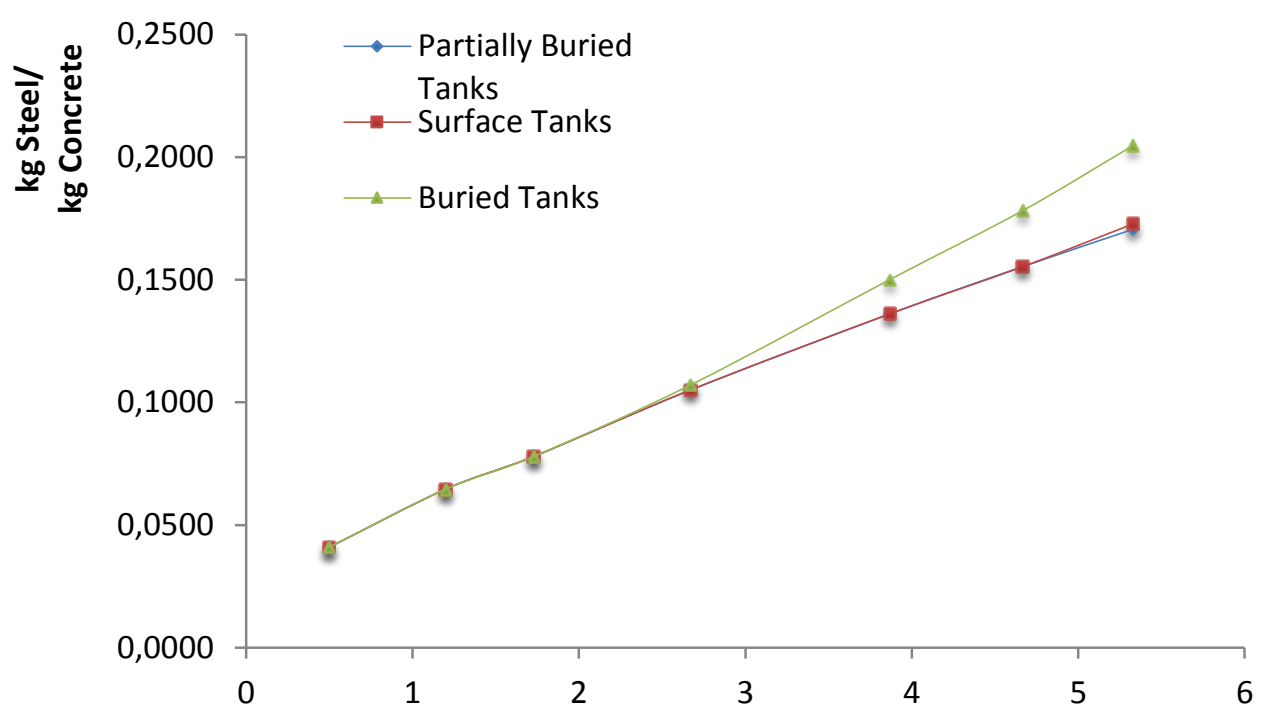

2R/Hw 


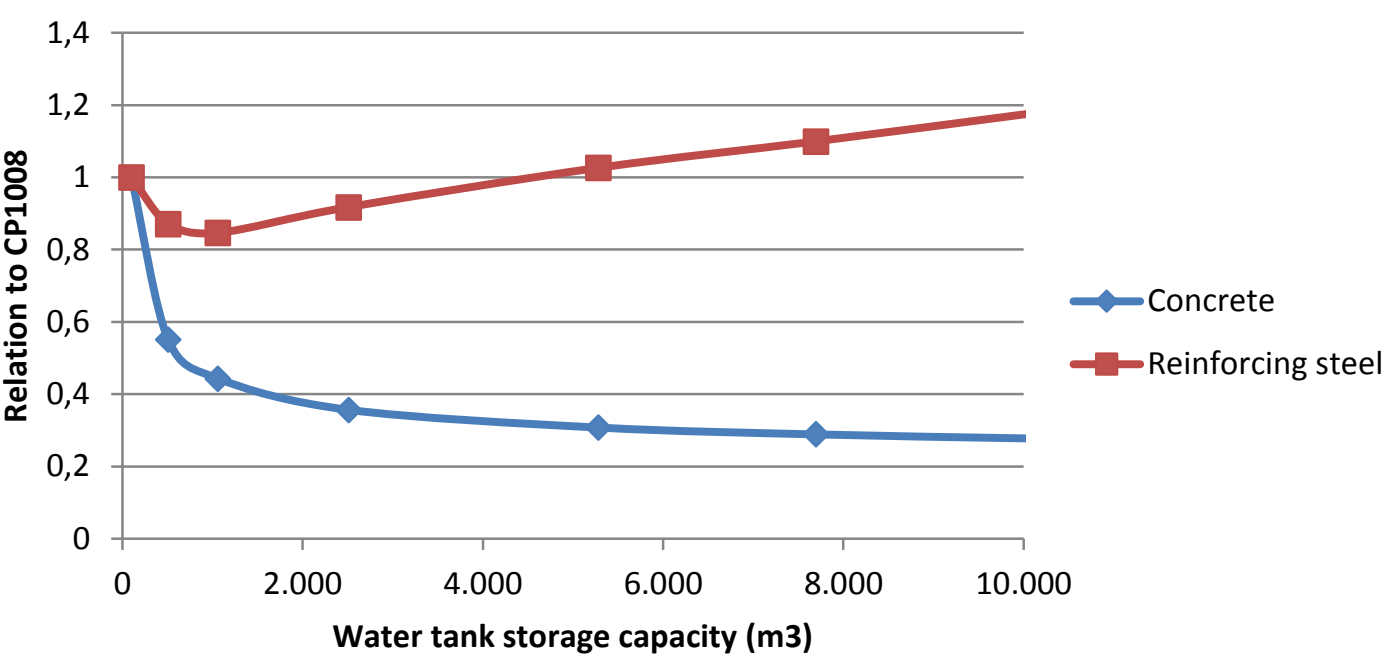

675

676

677 


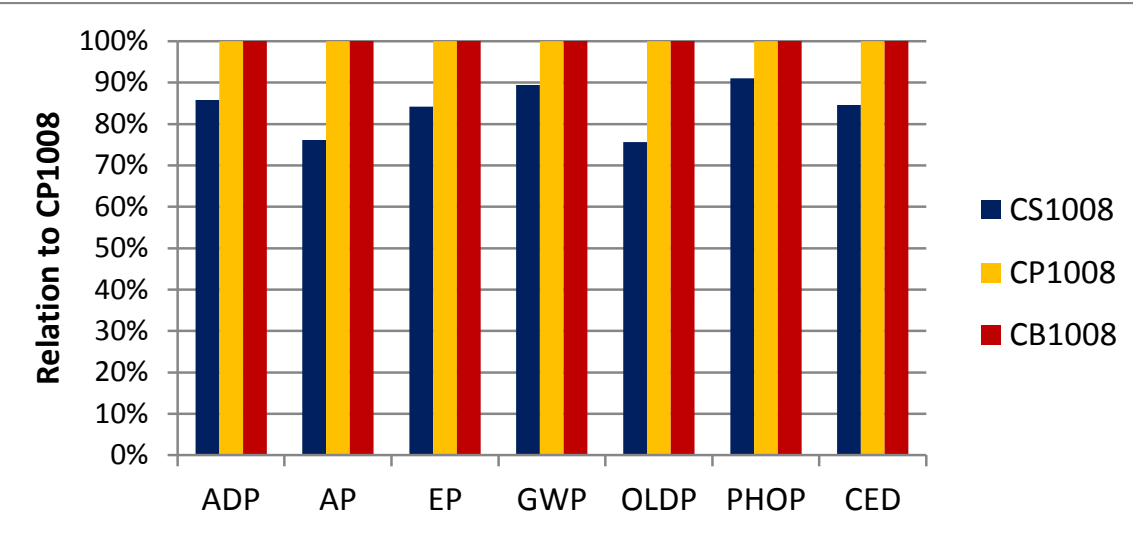

679

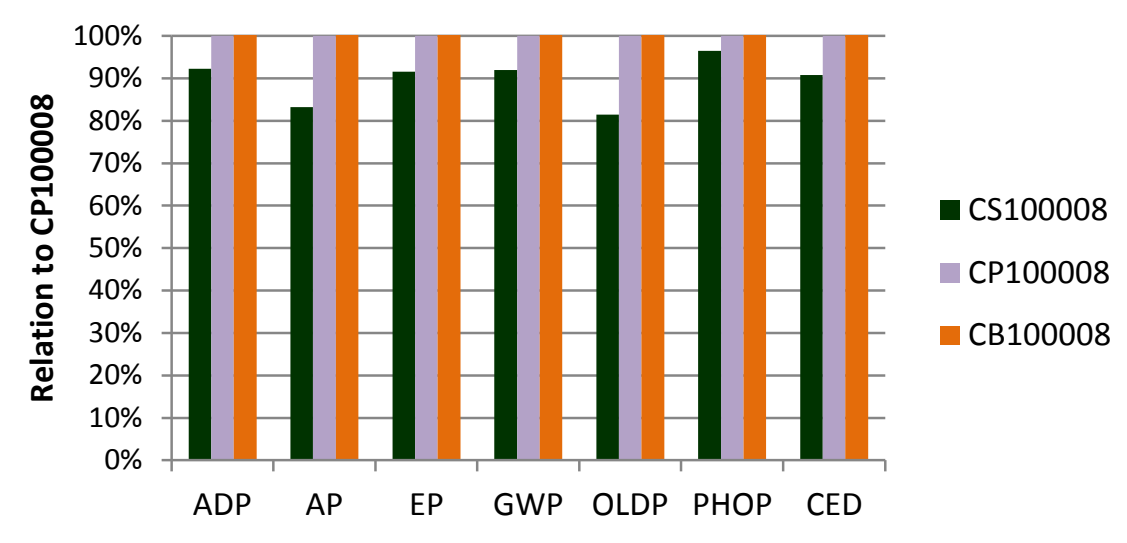

680

681

682 


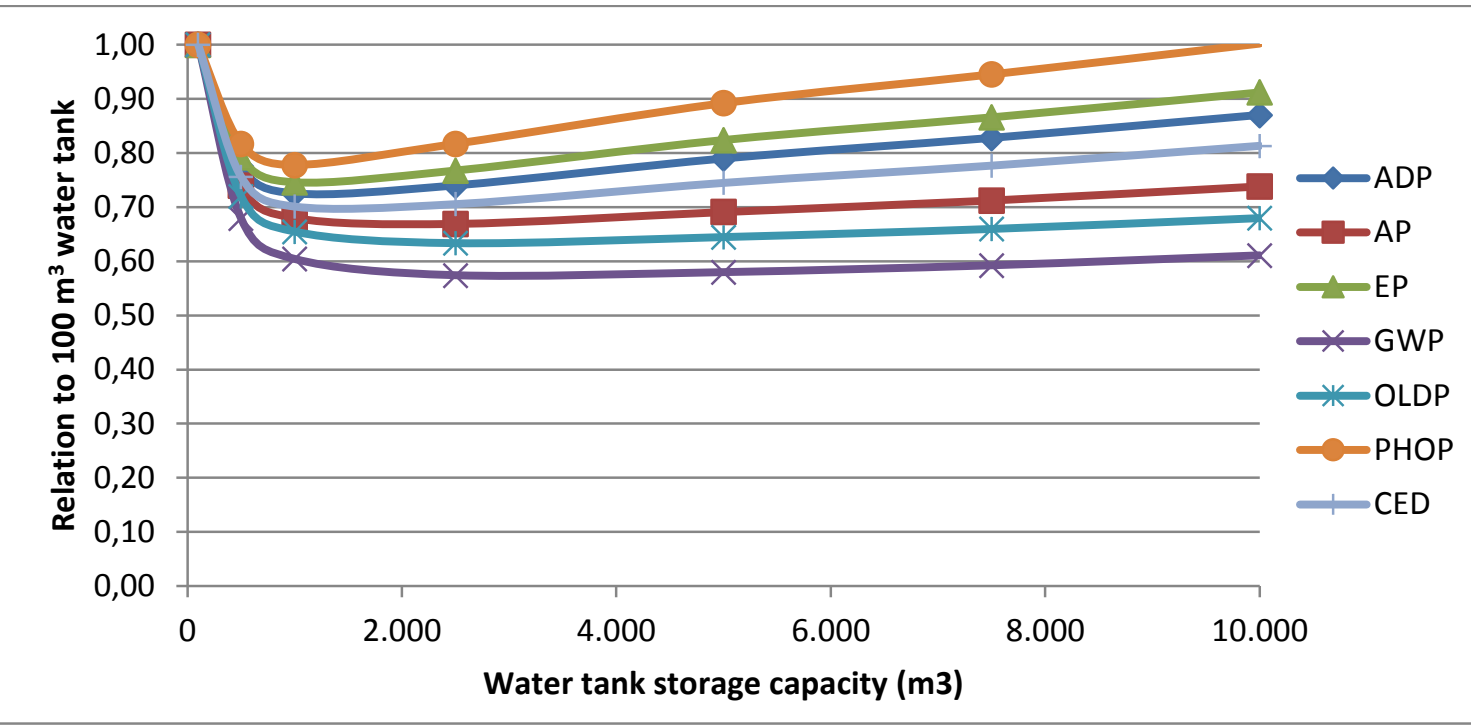

684

685 


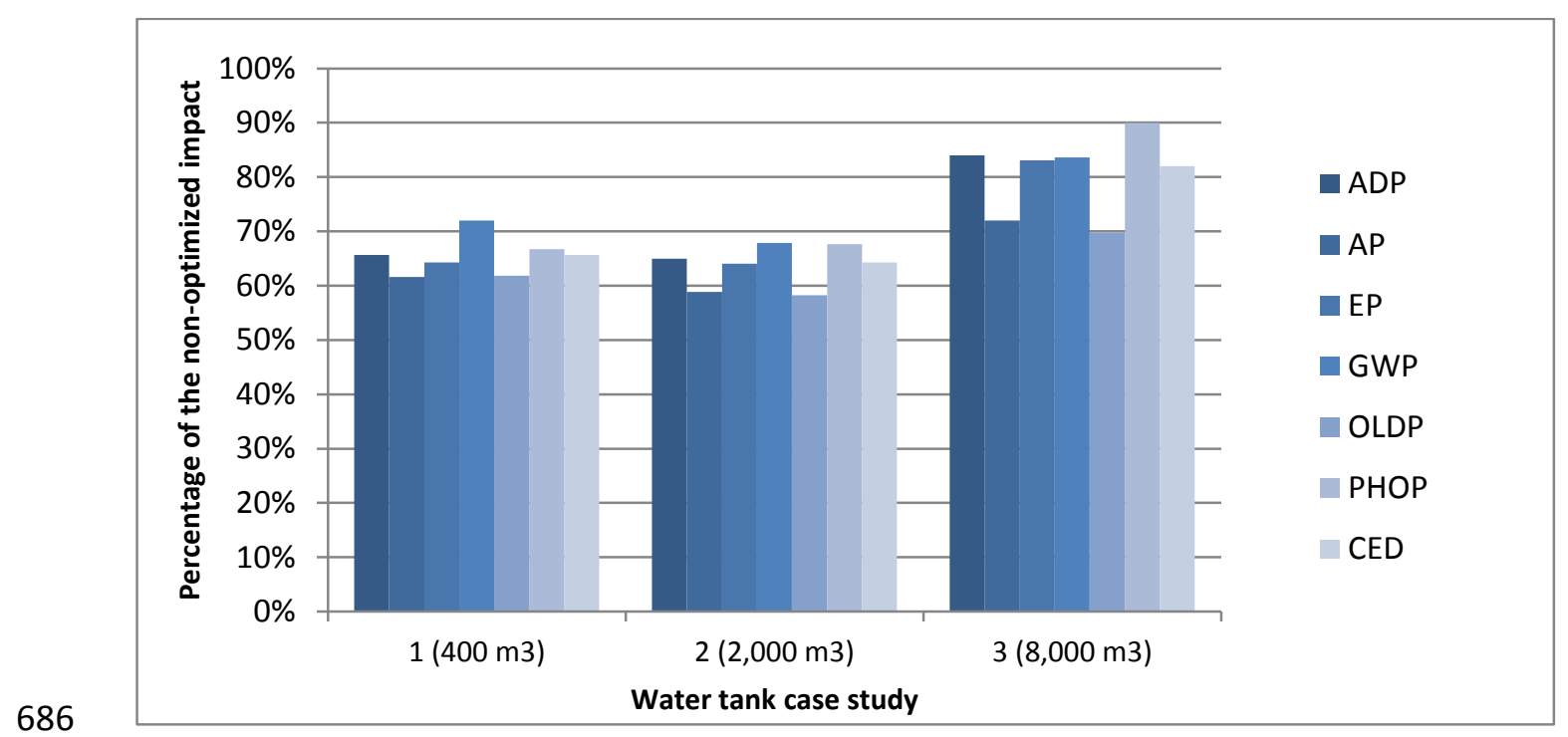

687

688 


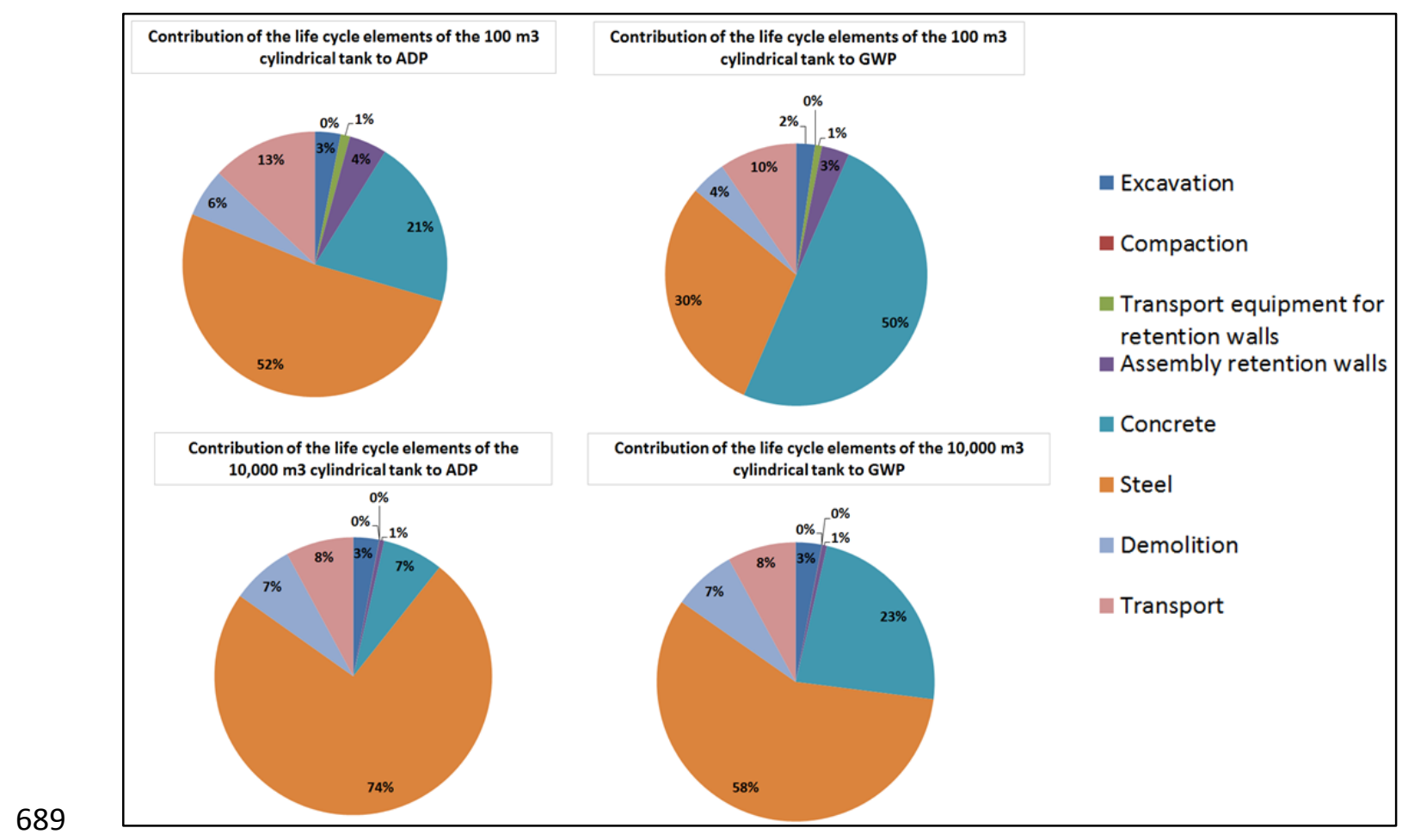

